\title{
Effect of Anodic Current Density on Characteristics and Low Temperature IR Emissivity of Ceramic Coating on Aluminium 6061 Alloy Prepared by Microarc Oxidation
}

\author{
Mohannad M. S. Al Bosta, ${ }^{1}$ Keng-Jeng Ma, ${ }^{2}$ and Hsi-Hsin Chien ${ }^{2}$ \\ ${ }^{1}$ Ph.D. Program in Engineering Science, College of Engineering, Chung Hua University, Hsinchu 30012, Taiwan \\ ${ }^{2}$ College of Engineering, Chung Hua University, Hsinchu 30012, Taiwan \\ Correspondence should be addressed to Mohannad M. S. Al Bosta; mmbosta2005@yahoo.com
}

Received 8 June 2013; Revised 7 November 2013; Accepted 10 November 2013

Academic Editor: Baolin Wang

Copyright (C) 2013 Mohannad M. S. Al Bosta et al. This is an open access article distributed under the Creative Commons Attribution License, which permits unrestricted use, distribution, and reproduction in any medium, provided the original work is properly cited.

\begin{abstract}
High emitter MAO ceramic coatings were fabricated on the Al 6061 alloy, using different bipolar anodic current densities, in an alkali silicate electrolyte. We found that, as the current density increased from $10.94 \mathrm{~A} / \mathrm{dm}^{2}$ to $43.75 \mathrm{~A} / \mathrm{dm}^{2}$, the layer thickness was increased from $10.9 \mu \mathrm{m}$ to $18.5 \mu \mathrm{m}$, the surface roughness was increased from $0.79 \mu \mathrm{m}$ to $1.27 \mu \mathrm{m}$, the area ratio of volcano-like microstructure was increased from $55.6 \%$ to $59.6 \%$, the volcano-like density was decreased from $2620 \mathrm{~mm}^{-2}$ to $1420 \mathrm{~mm}^{-2}$, and the $\gamma$-alumina phase was decreased from $66.6 \mathrm{wt} . \%$ to $26.2 \mathrm{wt} . \%$, while the $\alpha$-alumina phase was increased from $3.9 \mathrm{wt} . \%$ to $27.6 \mathrm{wt} . \%$. The sillimanite and cristobalite phases were around $20 \mathrm{wt} . \%$ and $9 \mathrm{wt} . \%$, respectively, for $10.94 \mathrm{~A} / \mathrm{dm}^{2}$ and approximately constant around $40 \mathrm{wt} . \%$ and less than $5 \mathrm{wt} . \%$, respectively, for the anodic current densities 14.58, 21.88, and $43.75 \mathrm{~A} / \mathrm{dm}^{2}$. The ceramic surface roughness and thickness slightly enhanced the IR emissivity in the semitransparent region $(4.0-7.8 \mu \mathrm{m})$, while the existing phases contributed together to raise the emissivity in the opaque region $(8.6-16.0 \mu \mathrm{m})$ to higher but approximately the same emissivities.
\end{abstract}

\section{Introduction}

The growing demand of limited energy sources requires adoption of effective methods to save energy consumption and to prevent unwanted energy loss. The high emitter surfaces enhance the thermal performance of heating and cooling systems and consequently reduce the needed energy $[1$, 2]. Several methods are applied to the material surfaces to enhance their emissivities, such as coating by thin tape films, paint and lacquer, roughening, and surface anodizing.

One of the promising coating methods is the microarc oxidation, MAO. The MAO ceramic coating has perfect properties such as wear resistance, corrosion resistance, hardness, strong adhesion, and thermal shock resistance and can be fabricated on the surfaces of aluminium, magnesium, and titanium alloys [3-62]. The properties of the MAO ceramic coating are affected by the electrolyte compositions [63-71], treatment time [14, 28, 70-75], electrolyte temperature [70, 76], voltage $[72,77-80]$, current density $[6,47,55,70,81-83]$, current mode $[84,85]$, and electrode geometry [86].
The applied current modes in the MAO process are DC, AC, unipolar, and pulsed bipolar. The pulsed bipolar mode was found to enhance the surface properties of treated metals, improve the thickness and homogeneity of oxide layers, and limit the growth of the porous layer $[6-8,54]$.

Coating aluminium with a high thermal radiator of MAO ceramic will find its applications in low profile devices, heat sinks, electronic parts, LED, lasers, refrigeration, air conditioning, transport industries, liquefaction plants, power plants, petroleum refineries, and others. Previous studies rarely demonstrated the IR emissivity of the MAO coatings. For example, Wang et al. [87] studied the IR emissivity at $500^{\circ} \mathrm{C}$ of MAO ceramic coating on 2024 aluminium substrates and illustrated that $\gamma-\mathrm{Al}_{2} \mathrm{O}_{3}$, silicon oxides, and phosphate oxides contributed to high emissivity at wavelengths 8-20 $\mu \mathrm{m}$, while the surface roughness was responsible for increasing emissivity at wavelength range $3-5 \mu \mathrm{m}$. Tang et al. [39] studied the emissivity of MAO ceramic prepared on Ti6Al4V substrate and reported that more Co contents 
enhanced the emissivity of the ceramic surface at $700^{\circ} \mathrm{C}$ and at wavelengths $3-20 \mu \mathrm{m}$. A relatively high emissivity was found by Wang et al. [88] when they studied the emissivity $\left(8-14 \mu \mathrm{m}, 700^{\circ} \mathrm{C}\right)$ of the surface of ceramic coating on Ti6Al2Zr1MolV alloy, and they pointed out that the $\mathrm{TiO}_{2}$ phases were contributed to enhance the emissivity.

The geometry of the MAO-treated samples plays a main role in the industrial applications as a finishing process. The first effect comes to mind (by keeping the current output of main power supply constant and changing the sample dimensions) is the variation of current density. Previous works kept the sample dimensions constant and changed the input current density. Khan et al. [6] fabricated MAO alumina ceramic coatings on $\mathrm{Al} 6082$ alloy using a DC current mode of densities ranged from $5 \mathrm{~A} / \mathrm{dm}^{2}$ to $20 \mathrm{~A} / \mathrm{dm}^{2}$ in various concentrations of $\mathrm{KOH}$ electrolytes at temperatures ranged between $20^{\circ} \mathrm{C}$ and $25^{\circ} \mathrm{C}$ for 30 minutes. They reported that the denser current formed thicker coatings with minimal stress level, dense morphology, and a relatively high content of $\alpha-\mathrm{Al}_{2} \mathrm{O}_{3}$ phase. Raj and Mubarak Ali [70] used different direct current densities $\left(5-20 \mathrm{~A} / \mathrm{dm}^{2}\right)$ for MAO treating of aluminium in the alkaline silicate electrolyte at $10^{\circ} \mathrm{C}$ for 45 minutes and obtained thicker coatings, higher growth rate, and coating ratio at $15 \mathrm{~A} / \mathrm{dm}^{2}$ of current density, but the $20 \mathrm{~A} / \mathrm{dm}^{2}$ of current density decreased these properties due to the dominant of electrolyte dissolution over the coating building. The effects of bipolar current density on MAO ceramic coating formed on titanium alloy were studied by Sun et al. [83] in an electrolyte of sodium aluminate and hypophosphate at $35^{\circ} \mathrm{C}$ for 70 minutes. The cathodic $\left(j_{c}\right)$ and anodic $\left(j_{a}\right)$ current densities ranged between 6 and $12 \mathrm{~A} / \mathrm{dm}^{2}$. They pointed out that the lowest ratio of $j_{a} / j_{c}$ formed a denser and thinner layer with more uniform microstructures and did not contain $\alpha$-alumina phase, while the highest $j_{a} / j_{c}$ ratio formed a thicker ceramic coating comprised of entirely $\alpha$ alumina phase with poor adhesion to the substrate.

The main aim of the present work is to change the sample dimensions and find out the effect of the anodic current density on the microstructural and compositional properties of the MAO ceramic coating and the resultant low-temperature IR emissivity.

\section{Experimental}

Rectangular pieces $\left(4 \times 4 \times 0.2 \mathrm{~cm}^{3}\right)$ of aluminium alloy 6061 (Mg 1\%, Si 0.65\%, Fe 0.7\%, Cu 0.3\%, Cr 0.2\%, Mn 0.15\%, Ti $0.15 \%$, and $\mathrm{Al}$ balance) were used as substrates in this study. The exposed surface was ground to a 1200 grit SiC finish using the water as a lubricant, followed by rinsing in the doubly distilled water and drying in the air, while the other side was totally insulated using a Teflon tape.

Four different assemblies were applied by mounting a different number of pieces into a 6061-Al alloy clamp to get $16,32,48$, and $64 \mathrm{~cm}^{2}$ of exposed working area to the electrolyte and consequently different applied current densities. The preparation of samples was conducted for 10 minutes in a fresh electrolyte which consisted of $0.046 \mathrm{M}$ sodium silicate and $0.042 \mathrm{M}$ sodium hydroxide, and the $\mathrm{PH}$ was 12.8 in a cooling and stirring bath which kept the electrolyte temperature below $17^{\circ} \mathrm{C}$. We used the pulse controller SPIK 2000A (Shen Chang Electric Co., Ltd., Taiwan) to generate an asymmetric bipolar pulsing mode with parameters of 200 , 200,360 , and $200 \mu \mathrm{s}$ for $t_{\mathrm{on}}^{+}, t_{\mathrm{off}}^{+}, t_{\mathrm{on}}^{-}$, and $t_{\mathrm{off}}^{-}$, respectively. Two electrical power supplies (PR Series, 650 V, 7.7 A, Matsusada) were connected to the pulse controller with $100 \mathrm{~V}, 3.5 \mathrm{~A}$ for $\mathrm{DC} 1$ and $500 \mathrm{~V}, 7.0 \mathrm{~A}$ for DC2, as shown in Figure 1. The samples were connected to the output E2, while another $243 \mathrm{~cm}^{2}$ aluminium 6061 plate was connected to E1. Only Al 6061 alloy touched the electrolysis solution to avoid any contamination due to diffusion of wires, electrodes, or screws. According to Figure 1, both electrodes (E1 and E2) were alternating between the cathodic and anodic biasing according to the output bipolar pulse; the DC2 supplied the sample in the anodic period, and the DCl supplied it in the cathodic period. The resultant peak anodic biasing current densities, $J_{a}$, were $10.94,14.58,21.88$, and $43.75 \mathrm{~A} / \mathrm{dm}^{2}$.

Unlike the sample, no microarc oxidation was occurred on the aluminium plate due to the relatively low voltage during its anodic period. To avoid the effect of chemical reaction with the plate surface, we renewed the plate for each MAO experiment, despite being in a good situation. After completing every treatment, the samples were immediately immersed and cleaned with distilled water and then dried and stored in a sealed container. Before any use or test, samples were cleaned using an ultrasonic bath of doubly distilled water, propanol, acetone, and again doubly distilled water, 10 minutes for each, followed by air drying in the fume hood.

Different 27 randomly selected places were captured for each sample by the SEM (S4160, Hitachi). We performed the image analysis using Image Pro Plus 7.0 software (Media Cybernetics, Inc.) to estimate the volcano-like microstructure area ratio. The density of volcano-like was estimated by dividing its total number over the total area of SEM frames for the same sample.

The elemental composition analysis of ceramic coating layers was carried out using Hitachi EDX S4800. Low-angle X-ray diffraction (CuK $\alpha$; XRD, X'Pert PRO MPD, PANalytical, The Netherlands) was used to obtain the XRD patterns of as-deposited ceramic coatings. We performed the semiquantitative analysis of the XRD spectra using the so-called reference intensity ratio method (RiR method, de Woolf and Visser [89]) by MATCH! software (V.1.11f, Crystal Impact $\mathrm{GbR}$ ) and selected the best fit phases and compositions, in addition to estimating their weight percentage.

For each sample, at least 16 different locations were studied to determine the average of surface roughness using a surface roughness tester (Mitutoyo, SJ310) and layer thickness using an eddy-current coating-thickness tester (Extech CG204).

We used a modified Fourier transform infrared spectroscopy (FTLA2000 Series Spectrometer, ABB) to analyze the IR emissivity of the samples at $70^{\circ} \mathrm{C}$, by comparing with a reference blackbody radiation in the wavelength ranging between $4 \mu \mathrm{m}$ and $16 \mu \mathrm{m}$. 


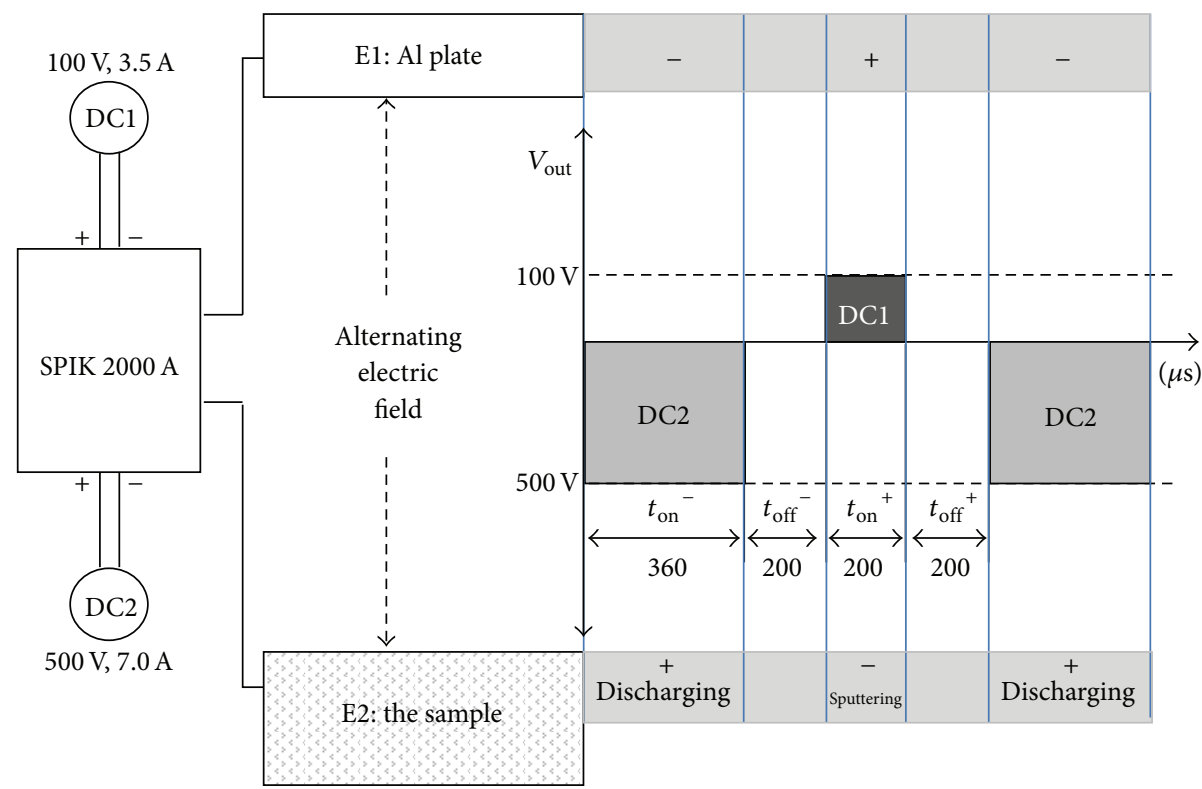

FIGURE 1: A scheme of the arrangement of power supplies and the pulse generator SPIK $2000 \mathrm{~A}$, in addition to the polarity of alternating electrodes according to the bipolar output pulse.

\section{Possible Chemical, Electrochemical Reactions and Phase Transformation}

Our MAO treatment was conducted in an electrolyte contained sodium hydroxide and sodium silicate. The samples were alternating between the cathodic and anodic polarizations as a result of the asymmetrical bipolar pulse mode, Figure 1. The forming of compositions and phases can be classified into four periods according to the bipolar pulse mode.

(a) $t_{\text {off }}^{+}$, a neutral period: where there is no applied voltage, the chemical reactions will etch the aluminium and release the aluminate ions $\mathrm{AlO}_{2}{ }^{-}$and $\mathrm{Al}(\mathrm{OH})_{4}{ }^{-}$into the electrolyte $[90,91]$ :

$$
\begin{gathered}
2 \mathrm{Al}+2 \mathrm{H}_{2} \mathrm{O}+2 \mathrm{OH}^{-}=2 \mathrm{AlO}_{2}{ }^{-}(\mathrm{aq})+3 \mathrm{H}_{2} \\
\mathrm{Al}+4 \mathrm{OH}^{-} \longrightarrow \mathrm{Al}(\mathrm{OH})_{4}{ }^{-}(\mathrm{gel})
\end{gathered}
$$

The chemical dissolution for the alumina ceramic reduces its thickness as given by the following reactions [91]:

$$
\begin{gathered}
\mathrm{Al}_{2} \mathrm{O}_{3}+2 \mathrm{OH}^{-}+3 \mathrm{H}_{2} \mathrm{O} \longrightarrow 2 \mathrm{Al}(\mathrm{OH})_{4}{ }^{-}(\mathrm{gel}) \\
\longrightarrow 2 \mathrm{Al}(\mathrm{OH})_{3} \downarrow+2 \mathrm{OH}^{-}
\end{gathered}
$$

The boehmite $\mathrm{AlO}_{2} \mathrm{H}$ also may be produced by the following reaction [92]:

$$
\mathrm{Al}(\mathrm{OH})_{4}{ }^{-}+\mathrm{H}_{2} \mathrm{O} \longrightarrow \mathrm{AlO}_{2} \mathrm{H} \downarrow+2 \mathrm{H}_{2} \mathrm{O}+\mathrm{OH}^{-}
$$

The $\mathrm{OH}^{-}$combines the aluminium hydroxide [8]:

$$
\mathrm{Al}(\mathrm{OH})_{3}+\mathrm{OH}^{-} \longrightarrow \mathrm{Al}(\mathrm{OH})_{4}{ }^{-}
$$

The aluminium oxidation $[8]$ is

$$
2 \mathrm{Al}+3 \mathrm{H}_{2} \mathrm{O}=\mathrm{Al}_{2} \mathrm{O}_{3}+3 \mathrm{H}_{2} \uparrow
$$

Based on the above, the alumina ceramic surface is chemically dissolved by the attack of $\mathrm{OH}^{-}[8]$, and this dissolution is more aggressive with the increment of liberated heat into the electrolyte from the treated surface.

(b) $t_{\text {on }}^{+}$, the cathodic period: in this period, the negatively charged sample attracts the electrolyte cations; the anions including the products of the neutral period will be repelled away into the electrolyte, and the possible reactions are as follows.

The inward deposition of cations into the ceramic surface equations is following

$$
\begin{aligned}
& \mathrm{Na}^{+}+\mathrm{e}^{-} \longrightarrow \mathrm{Na} \\
& \mathrm{Al}^{3+}+3 \mathrm{e}^{-} \longrightarrow \mathrm{Al}
\end{aligned}
$$

The sodium is a highly reactive metal and it will immediately react and dissolve into the electrolyte, (9), except that which penetrates into the inner layers of the ceramic:

$$
\mathrm{Na}+\mathrm{H}_{2} \mathrm{O}=\mathrm{Na}^{+}+\mathrm{OH}^{-}+\mathrm{H}_{2} \uparrow
$$

The water cathodic electrolysis is

$$
2 \mathrm{H}_{2} \mathrm{O}+2 \mathrm{e}^{-} \longrightarrow \mathrm{H}_{2} \uparrow+2 \mathrm{OH}^{-}
$$

(c) $t_{\text {off }}^{-}$, a neutral period: it has the same chemical reactions for the neutral period, $t_{\text {off }}^{+}$, (1)-(6).

(d) $t_{\text {on }}^{-}$, the anodic period: this period is characterized by the MAO discharging due to the effect of high electric field and the production of alumina ceramic by the reaction between the inward immigrant $\mathrm{O}^{2-}$ [93] and the outward immigrant $\mathrm{Al}^{3+}$ according to

$$
2 \mathrm{Al}^{3+}+3 \mathrm{O}^{2-} \longrightarrow \mathrm{Al}_{2} \mathrm{O}_{3}
$$




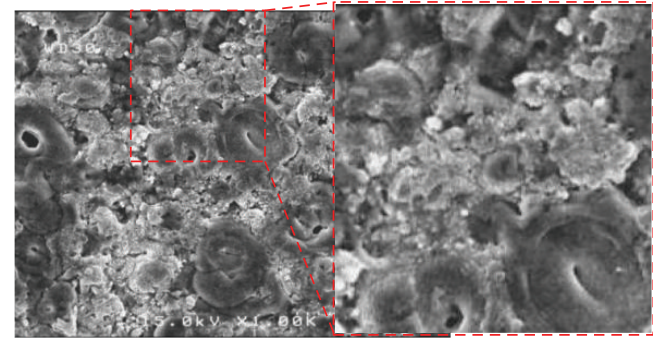

(a)

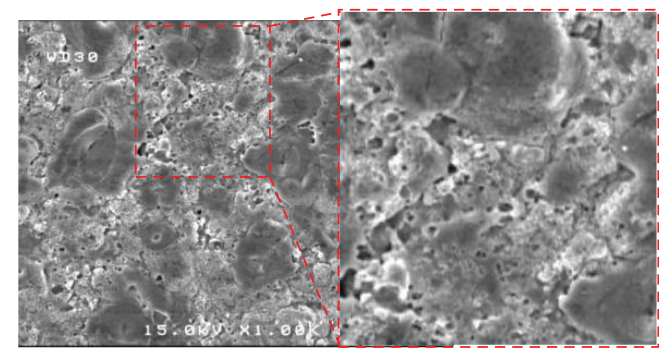

(b)

FIgURE 2: Two SEM micrographs for the same sample after MAO treatment by (a) a month and (b) six months.

Some of the immigrant $\mathrm{Al}^{3+}$ will be ejected into the electrolyte and combine with the hydroxide or silicate:

$$
\begin{gathered}
\mathrm{Al}^{3+}(\text { ejected })+3 \mathrm{OH}^{-} \longrightarrow \mathrm{Al}(\mathrm{OH})_{3} \downarrow \\
2 \mathrm{Al}^{3+} \text { (ejected) }+3 \mathrm{SiO}_{3}{ }^{2-} \longrightarrow \mathrm{Al}_{2}\left(\mathrm{SiO}_{3}\right)_{3}
\end{gathered}
$$

A part of silica will attach (without reaction) to the molten alumina and transfer into one of the silica phases, while another silica quantity combines with the ejected molten alumina and produces an aluminosilicate phase according to the transfer temperature and pressure:

$$
\mathrm{Al}_{2} \mathrm{O}_{3} \text { (molten) }+\mathrm{SiO}_{2} \stackrel{\Delta}{\rightarrow} \mathrm{Al}_{2} \mathrm{O}_{5} \mathrm{Si}
$$

The ejected molten alumina will contact the surrounding electrolyte, rapidly quenched and solidified, to form the $\gamma$ alumina phase [94]:

$$
\mathrm{Al}_{2} \mathrm{O}_{3} \stackrel{\text { rapid cooling }}{\longrightarrow} \gamma-\mathrm{Al}_{2} \mathrm{O}_{3}
$$

While the slower cooling rate in the inner layers of the sparking channels is favored to form the $\alpha$-alumina phase $[45,94]$,

$$
\mathrm{Al}_{2} \mathrm{O}_{3} \stackrel{\text { slow cooling }}{\longrightarrow} \alpha-\mathrm{Al}_{2} \mathrm{O}_{3}
$$

Heating the attached aluminium hydroxide and boehmite to an elevated temperature will transfer it into one of the alumina phases [95]:

$$
\begin{aligned}
& \mathrm{Al}(\mathrm{OH})_{3} \stackrel{450-750^{\circ} \mathrm{C}}{\longrightarrow} \gamma-\mathrm{Al}_{2} \mathrm{O}_{3} \\
& \mathrm{Al}(\mathrm{OH})_{3} \stackrel{>1100^{\circ} \mathrm{C}}{\longrightarrow} \alpha-\mathrm{Al}_{2} \mathrm{O}_{3} \\
& \mathrm{AlO}_{2} \mathrm{H} \stackrel{450-750^{\circ} \mathrm{C}}{\longrightarrow} \gamma-\mathrm{Al}_{2} \mathrm{O}_{3} \\
& \mathrm{AlO}_{2} \mathrm{H} \stackrel{>1100^{\circ} \mathrm{C}}{\longrightarrow} \alpha-\mathrm{Al}_{2} \mathrm{O}_{3}
\end{aligned}
$$

The anions will be attracted toward the surface during the anodic polarization and produce alumina and other compositions [10, 70]:

$$
\begin{gathered}
\left.\mathrm{Al}+4 \mathrm{OH}^{-} \longrightarrow \mathrm{Al}(\mathrm{OH})_{4}{ }^{-} \text {(gel }\right) \\
2 \mathrm{Al}+6 \mathrm{OH}^{-} \longrightarrow \mathrm{Al}_{2} \mathrm{O}_{3}+3 \mathrm{H}_{2} \mathrm{O}+6 \mathrm{e}^{-} \\
4 \mathrm{OH}^{-} \longrightarrow \mathrm{O}_{2}+2 \mathrm{H}_{2} \mathrm{O}+4 \mathrm{e}^{-}
\end{gathered}
$$

The silica is produced (24) by the combination between attracted silicate anions and $\mathrm{H}^{+}$which is produced by the water electrolysis on the anode (25)

$$
\begin{gathered}
\mathrm{SiO}_{3}{ }^{2-}+2 \mathrm{H}^{+} \longrightarrow \mathrm{SiO}_{2}+\mathrm{H}_{2} \mathrm{O} \\
2 \mathrm{H}_{2} \mathrm{O} \longrightarrow \mathrm{O}_{2}+4 \mathrm{H}^{+}+4 \mathrm{e}^{-}
\end{gathered}
$$

Generally, the chemical dissolution occurs during the anodic and neutral periods, the MAO only occurs during the anodic period, and the cathodic period does not contribute to the ceramic building or dissolution.

As a result of the previous reactions, the most likely compositions and phases on the surface of MAO-treated aluminium in the alkaline sodium silicate electrolyte are alumina phase/s, silica phase/s, and aluminosilicate phase/s, while other compositions mostly will be released or dissolved in the electrolyte or in water during the cleaning process.

\section{Results}

After the preparation by a month and six months, the samples were studied by the SEM and XRD. A disappearance of some small particles was notified in the accumulated particles region, as shown in Figure 2. By comparing the XRD patterns, a strong peak for cristobalite (an $\mathrm{SiO}_{2}$ phase) and other small peaks were almost vanished, Figure 3, which suggested that these released particles mostly consist of the cristobalite phase. The small size cristobalite particles provide more surface area or surface energy, which are prone to be dissolved in water or other solvents during cleaning process, which tends to enhance the detachment of cristobalite particles [96]. Due to this phenomenon, all presented measurements and results in this study belong to the samples after six months of treatment.

A linear correlation occurred for the layer thickness and surface roughness with the current densities $J_{a} \leq$ $21.88 \mathrm{~A} / \mathrm{dm}^{2}$, followed by a deflection from the linearity for the highest current density, as shown in Figures 4(a) and 4(b). The thinnest coating $10.9 \mu \mathrm{m}$ was formed at the lowest current density $10.94 \mathrm{~A} / \mathrm{dm}^{2}$, while the thickest coating $18.5 \mu \mathrm{m}$ was formed at the highest current density $43.75 \mathrm{~A} / \mathrm{dm}^{2}$. The surface roughness ranged between $0.79 \mu \mathrm{m}$ and $1.27 \mu \mathrm{m}$ for current densities $10.94 \mathrm{~A} / \mathrm{dm}^{2}$ and $43.75 \mathrm{~A} / \mathrm{dm}^{2}$, respectively. Similar response of thickness-current density was found 


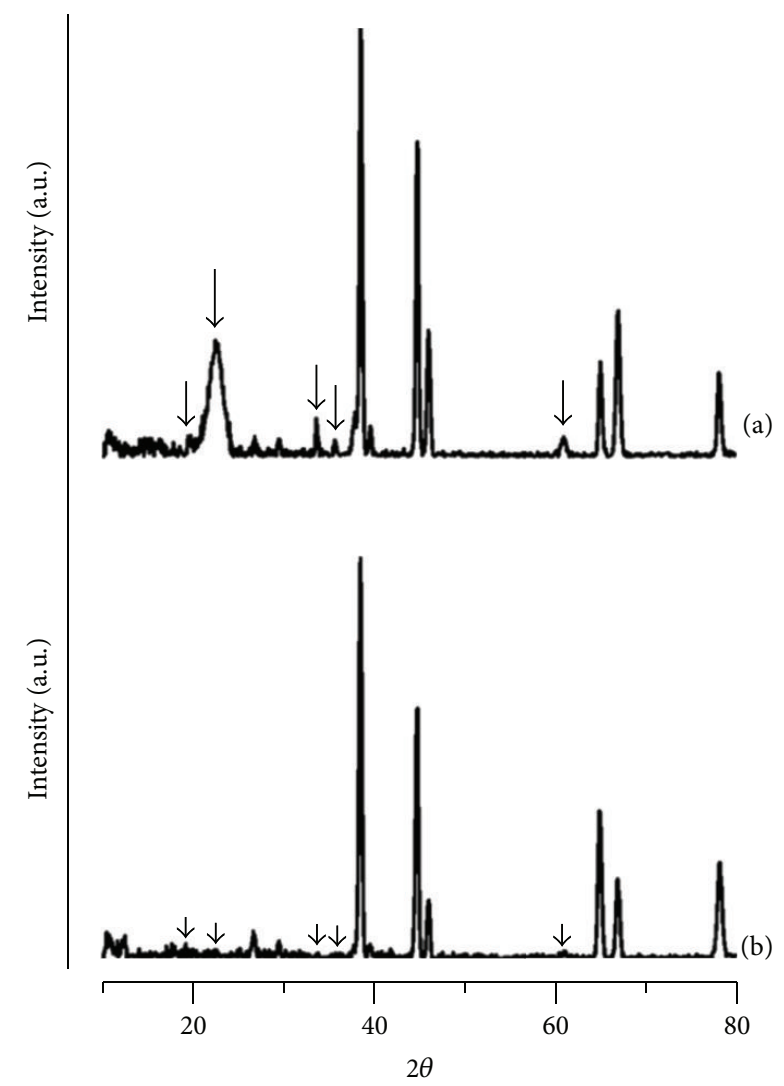

FIGURE 3: XRD patterns of a sample after the MAO treatment by (a) a month and (b) six months. The arrows are pointing to the peaks which were decreased significantly after six months of storage.

using DC current by Raj and Mubarak Ali [70]. A linear correlation between the MAO alumina ceramic thickness and roughness is illustrated in Figure 5, which is consistent with some previously published works [87, 97, 98].

Figure 6 illustrates the apparent microstructures in the SEM micrographs, which can be classified into accumulated particles, microcracks, and volcano-like microstructures. A volcano-like microstructure includes a solidified pool and a centered open/blind crater. The volcano-like microstructures are formed by the discrete localized microdischarge events. The rapid solidification of the molten alumina forms the microcracks and accumulated particles on and around the discharge channels [99]. Wei et al. [45] reported that more $\alpha$-alumina can be formed in the inner layers due to the low cooling rate, while the high cooling rate on the outer layer surface was favorable to form more $\gamma$-alumina during the solidification.

The increment of anodic current density significantly affected the size of volcano-like as presented in Figures 7(a)-7(d). Smallest volcano-like microstructures with more population occurred for the lowest $J_{a}\left(10.94 \mathrm{~A} / \mathrm{dm}^{2}\right)$, while the largest volcano-like microstructures associated with the highest $J_{a}\left(43.75 \mathrm{~A} / \mathrm{dm}^{2}\right)$. To get more comprehensive results, an average of 27 different randomly selected positions were captured by the SEM for each sample and digitally analyzed by the Image-Pro Plus software to estimate the ratio of the occupied area by the volcano-like microstructures to the micrograph frame, and the results are presented in Figure 8. A slight increment in the area ratio from $55.6 \%$ to $59.6 \%$ occurred for the occupied area ratio of the volcano-like microstructures due to the increment of the $J_{a}$ from $10.94 \mathrm{~A} / \mathrm{dm}^{2}$ to $43.75 \mathrm{~A} / \mathrm{dm}^{2}$. On the contrary, a significant decrement from $2620 \mathrm{~mm}^{-2}$ to $1420 \mathrm{~mm}^{-2}$ was accomplished in the volcano-like density due to the increment of anodic current density, as shown in Figure 9.

Figure 10 shows the elemental compositions of several EDX study points over samples prepared at various anodic current densities. For all samples, the aluminium was dominant near to the craters, while its concentration was decreased as the study point moved away from the craters. More silicon was found in the accumulated particles, Figures 10(a)-10(d). Few sodium amounts were found in the accumulated particles of the MAO ceramic surface prepared at $43.75 \mathrm{~A} / \mathrm{dm}^{2}$.

Figure 11 shows the XRD patterns of MAO alumina ceramics prepared at various anodic biasing current densities. The most apparent peaks belong to aluminium due to the $\mathrm{X}$ ray penetration into the substrate through the ceramic layer. To identify the compositions and phases related to other shorter peaks, we applied the RiR method by MATCH! software. The other major phases were $\alpha$-alumina, $\gamma$-alumina, cristobalite (an $\mathrm{SiO}_{2}$ phase), and sillimanite (an $\mathrm{Al}_{2} \mathrm{SiO}_{5}$ phase), while there were few amounts of $\mathrm{Si}$ and $\mathrm{Na}$ which are localized in the inner ceramic layer. The weight percentages of the major phases are presented in Figure 12 after subtracting the weight percentages of $\mathrm{Al}, \mathrm{Si}$, and $\mathrm{Na}$. The $\gamma$-alumina phase was the dominant in the ceramic coating at low anodic current density. As the anodic current density increased, the $\gamma$-alumina decreased from $66.6 \mathrm{wt} . \%$ to $26.2 \mathrm{wt} . \%$, while the $\alpha$-alumina phase increased from $3.9 \mathrm{wt} . \%$ to $27.6 \mathrm{wt} . \%$. The sillimanite was around $20 \mathrm{wt} . \%$ for the lowest anodic current density of $10.94 \mathrm{~A} / \mathrm{dm}^{2}$ and approximately constant around $40 \mathrm{wt} . \%$ for anodic current densities of 14.58, 21.88, and $43.75 \mathrm{~A} / \mathrm{dm}^{2}$. The cristobalite was $9 \mathrm{wt} . \%$ for anodic current density of $10.94 \mathrm{~A} / \mathrm{dm}^{2}$ and less than $5 \mathrm{wt} . \%$ for $J_{a} \geq$ $14.58 \mathrm{~A} / \mathrm{dm}^{2}$.

Figure 13 shows the infrared spectra of MAO ceramic surfaces prepared at different anodic current densities, in addition to an untreated saw cut aluminium surface. The measurements were conducted at $70^{\circ} \mathrm{C}$; the shaded rectangles belong to the absorption bands of $\mathrm{CO}_{2}$ (centered at 4.3 and $14.9 \mu \mathrm{m}$ ) and $\mathrm{H}_{2} \mathrm{O}$ (centered at $6.1 \mu \mathrm{m}$ ) in the ambient air [100-104]. The MAO ceramic surfaces have higher emissivity values compared to the untreated saw cut aluminium surface.

The emissivity spectrum has three distinguishable wavelength regions. The emissivity increased with the wavelength increment in the first region, between $4.0 \mu \mathrm{m}$ and $7.8 \mu \mathrm{m}$. The second region is characterized by a rapid ascending that starts from $7.8 \mu \mathrm{m}$ and ends at $8.6 \mu \mathrm{m}$. The third region for wavelengths longer than $8.6 \mu \mathrm{m}$ is characterized by a relatively high emissivity with three apparent peaks centered at $10.2 \mu \mathrm{m}$, $12.8 \mu \mathrm{m}$, and $15.5 \mu \mathrm{m}$. The high intensity values of the peak at $10.2 \mu \mathrm{m}$ ranged between $96.6 \%$ and $97.4 \%$ for $10.94 \mathrm{~A} / \mathrm{dm}^{2}$ and $43.75 \mathrm{~A} / \mathrm{dm}^{2}$, respectively. 


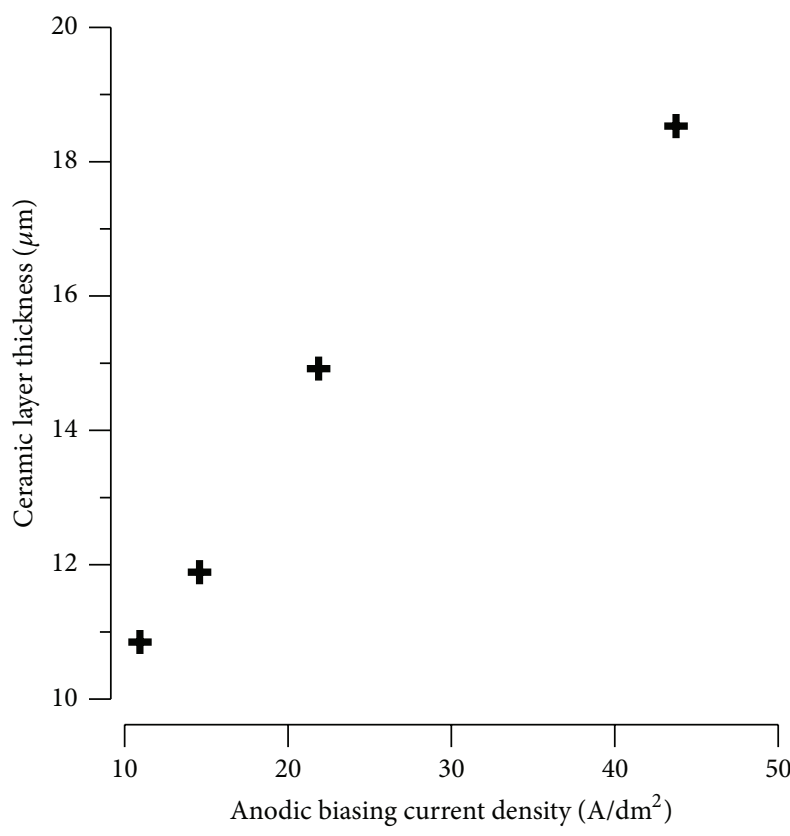

(a)

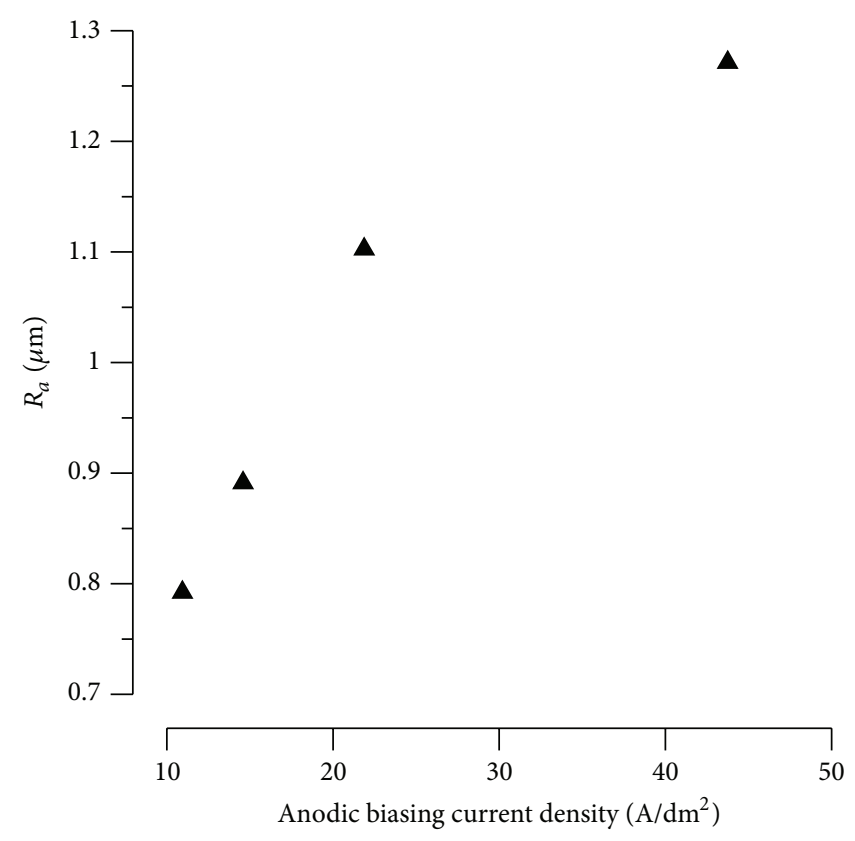

(b)

FIGURE 4: The effect of anodic biasing current density on the (a) layer thickness and (b) surface roughness of the MAO ceramic coating.

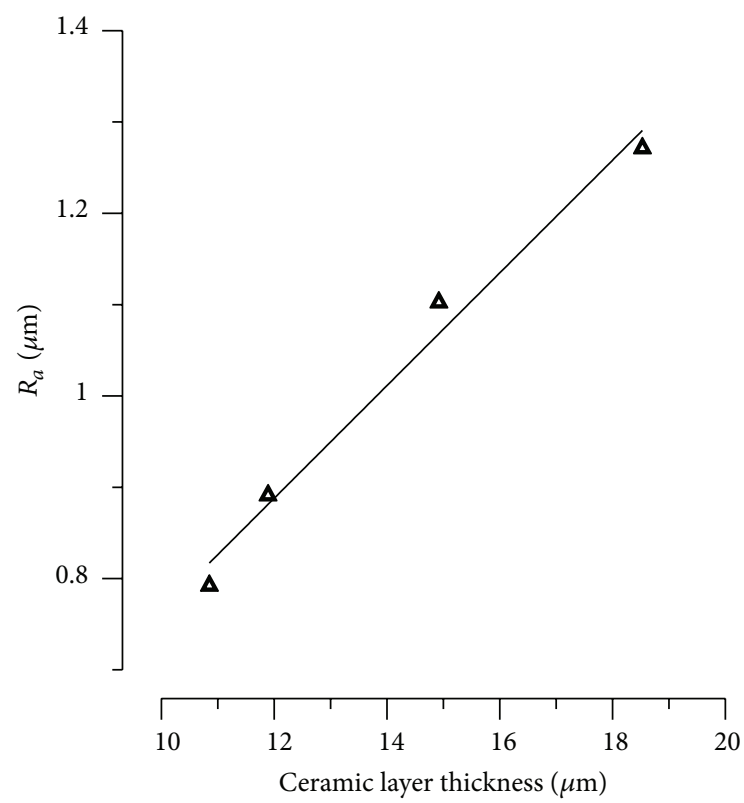

FIGURE 5: The linear correlation between the MAO ceramic thickness and surface roughness.

\section{Discussions}

At the first beginning of the MAO process, the relatively high anodic voltage activates the inward oxidation of the aluminium substrate by the reaction between the inward immigrant $\mathrm{O}^{2-}$ and the outward immigrant $\mathrm{Al}^{3+}$ according to (11) [93]. The growth of aluminium oxide layer increases the electrical resistance, and at a specific thickness, the current begins to flow through weak points on the oxide layer and

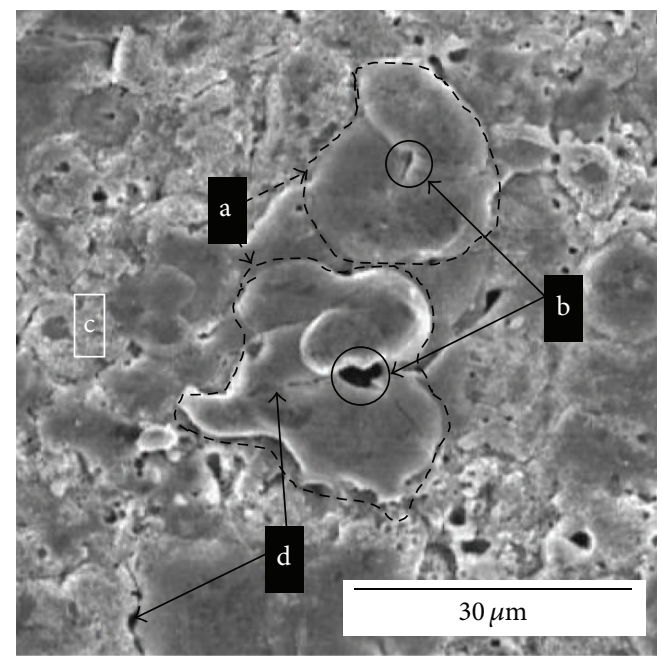

FIGURE 6: The main microstructures in the SEM micrographs are (a) resolidified pools, (b) craters, (c) accumulated particles, and (d) microcracks.

strengthens the electrical field, which in turn significantly increases the reionization of the surrounding electrolyte and the aluminium substrate and consequently triggers the plasma microdischarges. The elevated temperature of localized plasma (which ranges between $2 \mathrm{kK}$ [105] and $11 \mathrm{kK}$ [106]) melts the alumina and vaporizes the electrolyte in the discharging circumference and evacuates the region of plasma discharging. Due to the pressure reduction, the molten alumina will be suctioned out of the discharging channel and the electrolyte flows toward the low pressure region and will be vaporized by the molten alumina. Some of 


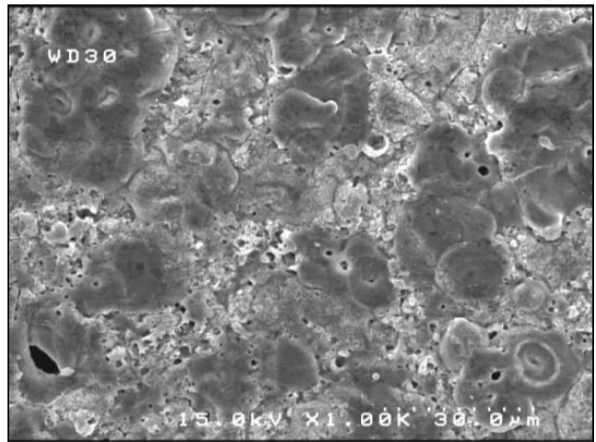

(a)

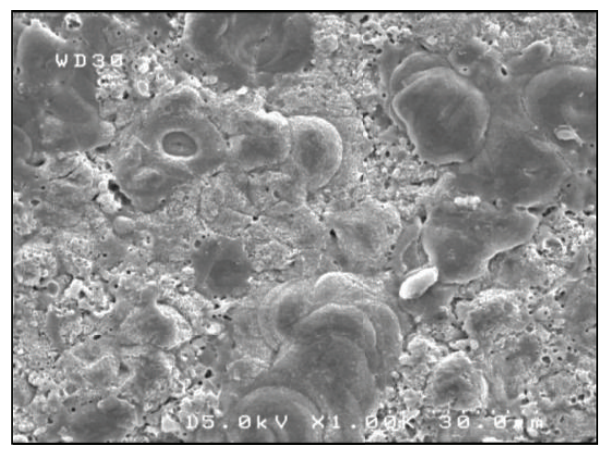

(c)

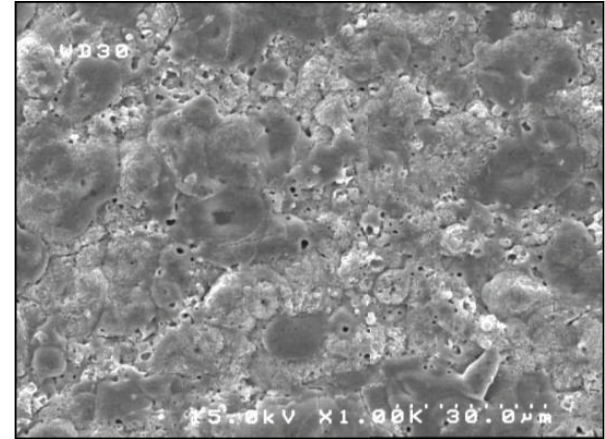

(b)

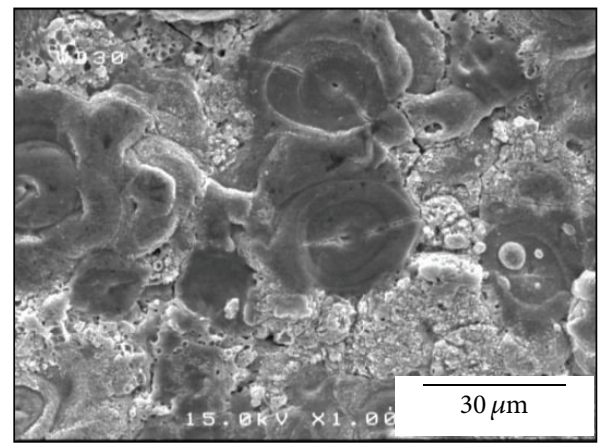

(d)

FiguRE 7: Surface morphologies of MAO ceramic coatings prepared at different anodic biasing current densities: (a) $10.94 \mathrm{~A} / \mathrm{dm}^{2}$, (b) $14.58 \mathrm{~A} / \mathrm{dm}^{2}$, (c) $21.88 \mathrm{~A} / \mathrm{dm}^{2}$, and (d) $43.75 \mathrm{~A} / \mathrm{dm}^{2}$.

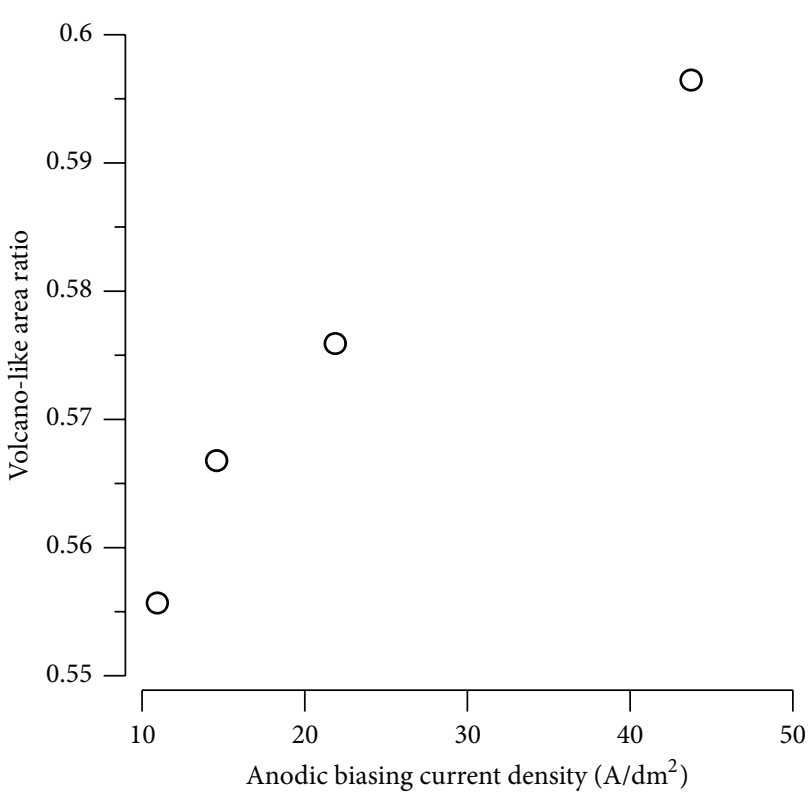

FIGURE 8: The effect of anodic current density on the relatively occupied area by volcano-like microstructures.

solid molecules, such as silica, and ions may be attached on the surface of molten alumina, which forms the cristobalite and sillimanite phases which were found on the accumulated particles and on the solidified pools according to the EDX and

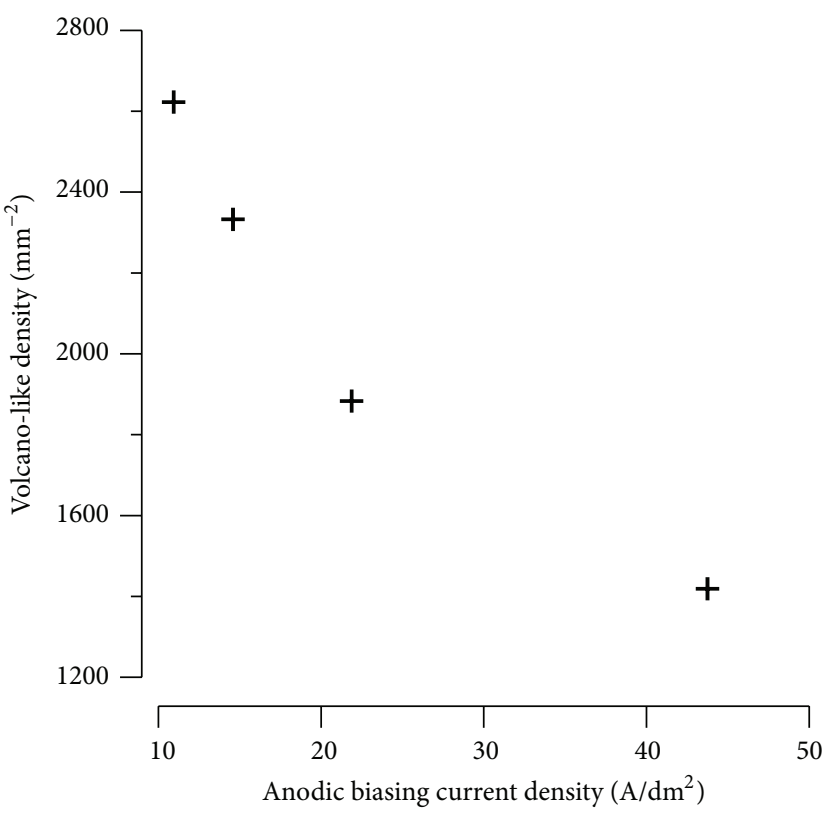

FIgURE 9: The inverse proportional of volcano-like density with the anodic current density.

XRD results. The volcano-like microstructures are created by the solidification of the molten alumina which spread over the surface around the discharging channels forming the solidified pools and the craters. According to the EDX 


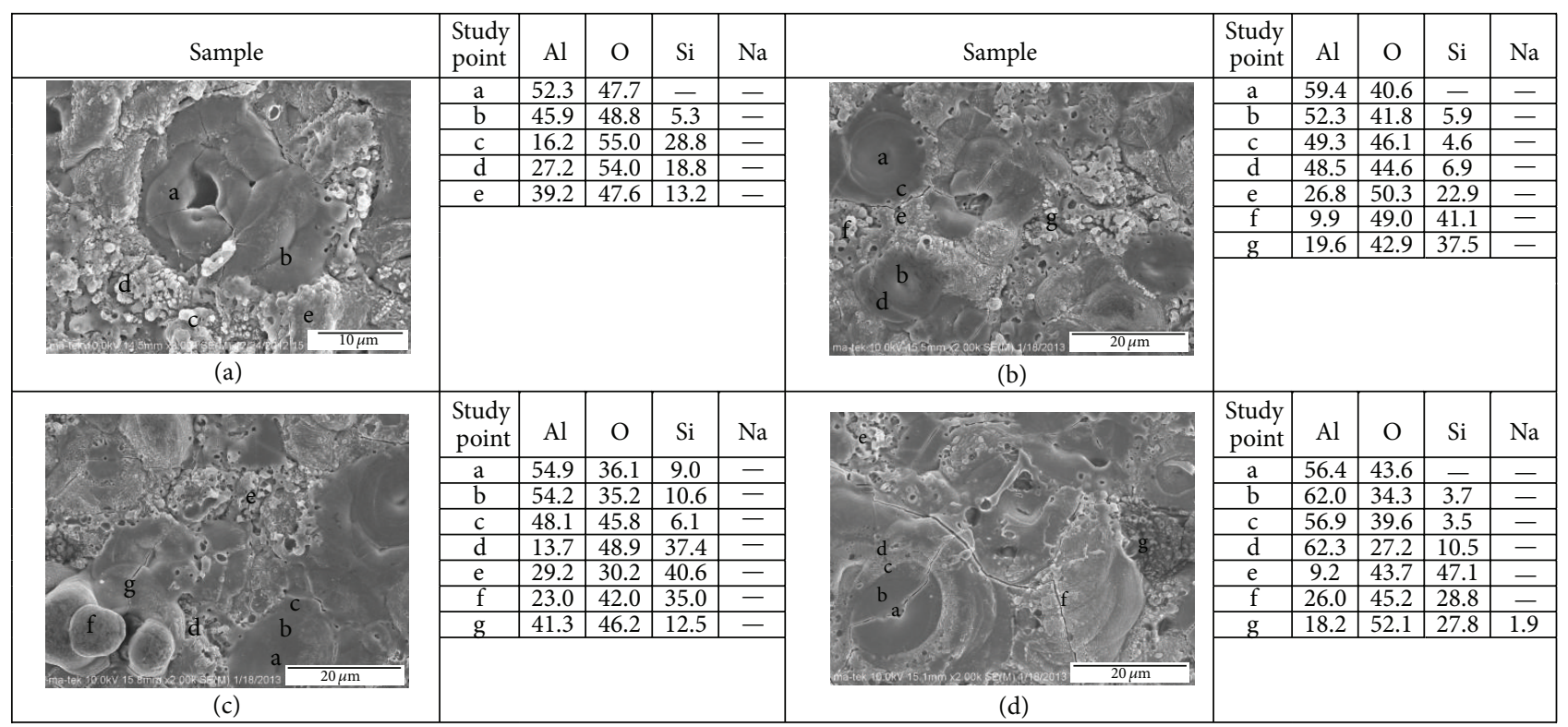

FIGURE 10: The results of the EDX analysis at several locations on the MAO ceramic surfaces prepared at different anodic current densities: (a) 10.94, (b) 14.58 , (c) 21.88 , and (d) $43.75 \mathrm{~A} / \mathrm{dm}^{2}$.

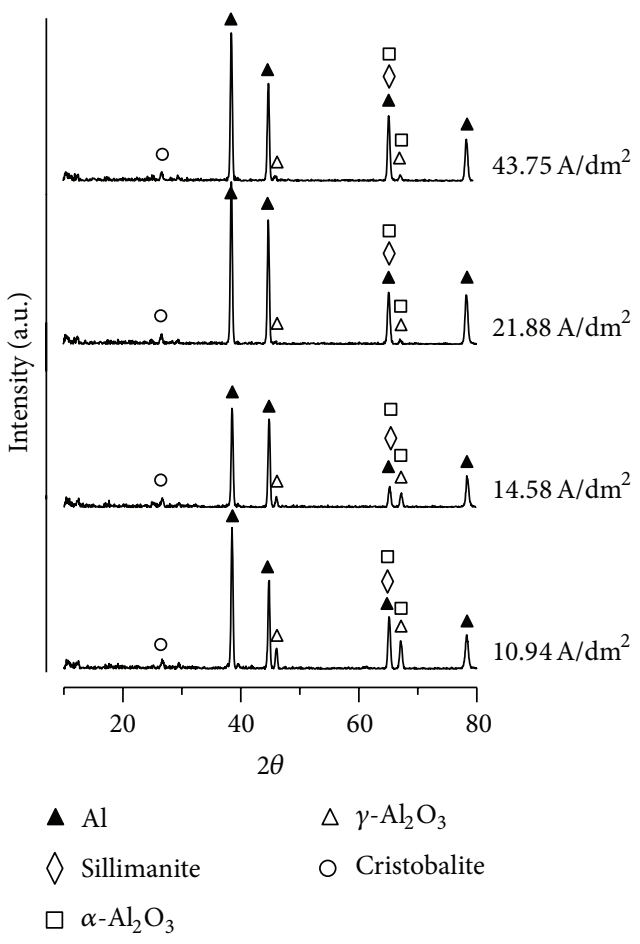

FIGURE 11: XRD spectra for MAO alumina ceramic coatings prepared at different anodic current densities. The most apparent peaks are for aluminium, which minimize the appeared intensities for other phases and compositions.

results, more silicon was found on the accumulated particles and the edges of the solidified pools, which were identified by the XRD results to be the cristobalite and sillimanite phases. The increment of cristobalite and sillimanite phases on the accumulated particles and edges of solidified pools was because of the longer travelling distance during the ejection of alumina out of the discharging channel, which allowed more silica to be attached. After the solidification, the surface tension forms the microcracks and the accumulated small particles on the solidified pool edges which contain more cristobalite and sillimanite phases [107]. Also, the EDX results stated that the aluminium concentration increased as the study point approached the crater; this reflects that less reaction happened between the center of ejected molten alumina and the silica due to the flow of the vaporized electrolyte which might start from the edges and consequently more silica was attached on the edges.

Figure 4 states the effect of anodic current density on the layer thickness and surface roughness. The small working area increased the current density which resulted in stronger microdischarges and consequently ejected more molten alumina out of the discharging channels, which increased the growth of the MAO ceramic coating, Figure 4(a). As the MAO ceramic grew, the current flowed through less weak points, which strengthened the electrical plasma discharges and produced wider volcano-like microstructures, Figure 7(d), less volcano-like density, Figure 9, and a rougher surface, Figure 4(b). The stronger microdischarges liberated more elevated temperature and vaporized more electrolytes which in turn formed an envelope of gas which surrounded the working area and slowed the cooling rate and was favorable to form more $\alpha$-alumina phases, Figure 12(a). The growth of the ceramic layer, Figure 4(a), was less at the highest current density, $43.75 \mathrm{~A} / \mathrm{dm}^{2}$, due to the increment of liberated heat which increased the chemical dissolution around the working area [70].

The alumina ceramic is semitransparent in the range 4$7.7 \mu \mathrm{m}$ and opaque in the $7.7-25.0 \mu \mathrm{m}$ range as reported by Rozenbaum et al. [108]. Boumaza et al. found that the $\gamma$-alumina has a broadband between $11.1 \mu \mathrm{m}$ and $33.3 \mu \mathrm{m}$ [109], 


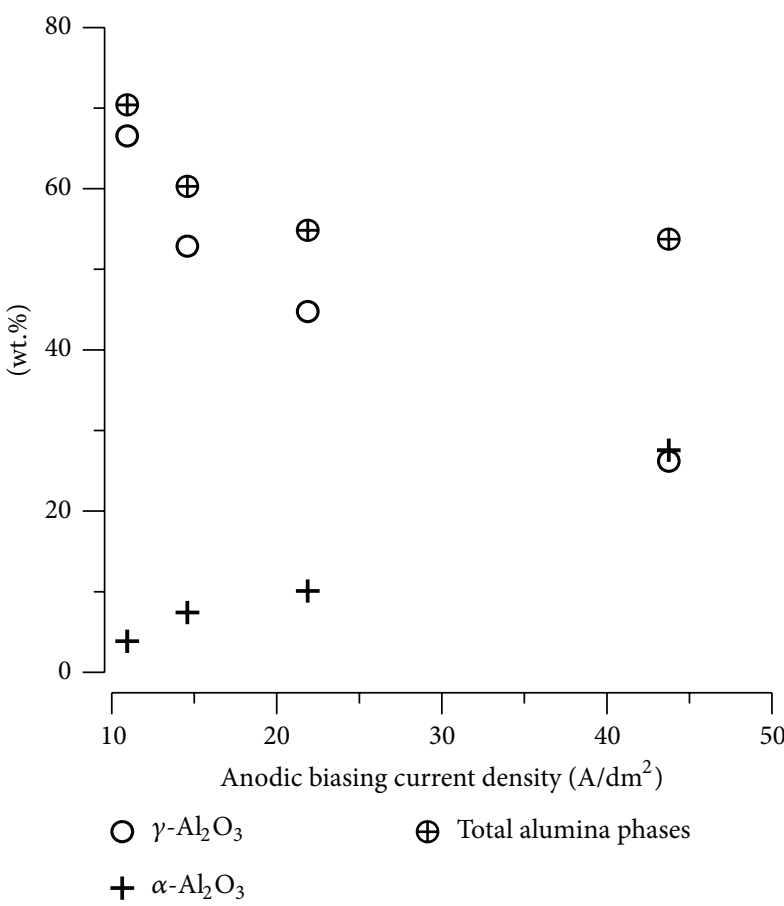

(a)

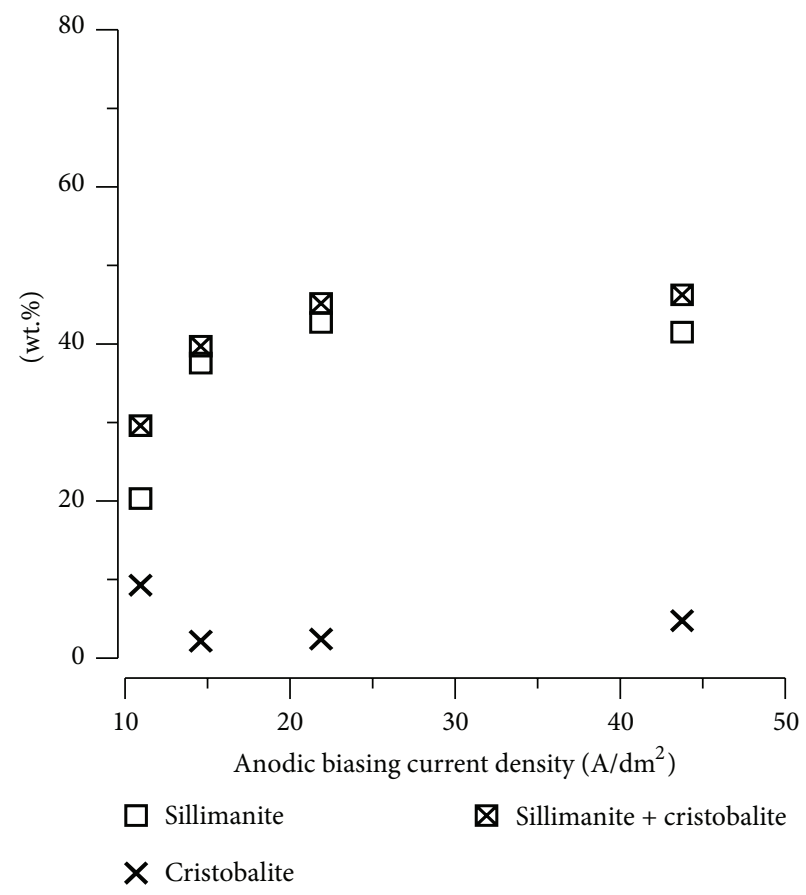

(b)

FIGURE 12: Effect of anodic current density on the MAO ceramic: (a) alumina phases and (b) sillimanite and cristobalite phases.

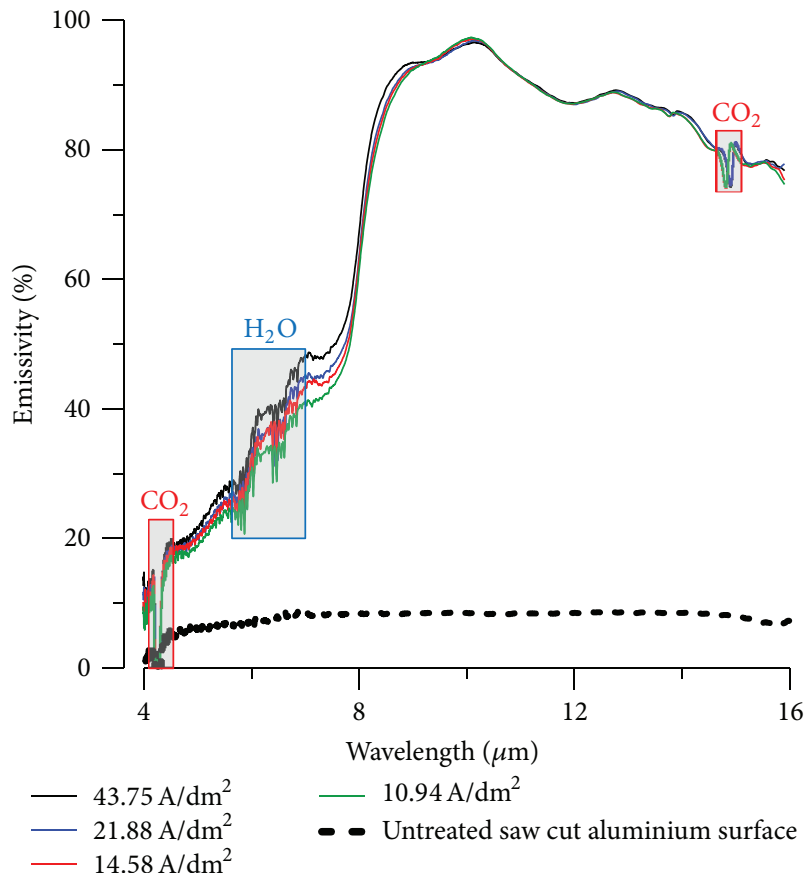

FIGURE 13: IR spectral emissivity of the MAO ceramic surfaces prepared at different anodic current densities.

and the $\alpha$-alumina has IR band positions at 15.50 and $16.45 \mu \mathrm{m}$ [109]. The cristobalite phase has IR peaks at 9.6, 11.4, 12.5 , and $15.3 \mu \mathrm{m}$, measured at $300^{\circ} \mathrm{C}$, which shift into longer wavelengths at lower temperatures [110]. The sillimanite phase has IR peaks at $10.75,11.63,13.16$, and $15.15 \mu \mathrm{m}$, and a broadband ranges from $8.55 \mu \mathrm{m}$ to $9.80 \mu \mathrm{m}$ [111]. These facts explain the behavior of IR emissivity spectra in Figure 13. For the range between $4.0 \mu \mathrm{m}$ and $7.8 \mu \mathrm{m}$, the ceramic alumina is semitransparent and its emissivity is lower than that in the region $(8.6-16.0 \mu \mathrm{m})$ where the ceramic turns to be opaque and stronger emitter due to the existence of $\gamma$ alumina and other phases. The existing phases contributed to enhancing the emissivity in the opaque region, and the apparent peaks centered at $10.2 \mu \mathrm{m}$ and $12.8 \mu \mathrm{m}$ were formed by the cristobalite and sillimanite, while the $15.5 \mu \mathrm{m}$ was formed by the $\alpha$-alumina and cristobalite phases.

Previous studies showed that the infrared emissivity of ceramic surfaces depends on its chemical and physical properties such as compositions, phases, roughness, porosity, grain size, pore size, spatial repetition of the grains, and layer thickness, and each wavelength region has its own effective factors $[88,98,108,112]$. According to Figure 13, the intensity of emissivity has a slight variation in the semitransparent region, whereas no significant variation occurred in the opaque region. Referring to the phase concentrations in Figure 12, the lowest current density formed 9 and $20 \mathrm{wt} . \%$ of cristobalite and sillimanite phases, respectively, while their weight percentages were approximately constants for $J_{a} \geq 14.58 \mathrm{~A} / \mathrm{dm}^{2}$. The $\alpha$ - and $\gamma$-alumina phases are semitransparent for the wavelengths shorter than $7.7 \mu \mathrm{m}$. On the other hand, both of the surface roughness and layer thickness were increased with the $J_{a}$. This leads to the conclusion that the slight variation of the emissivity in the semitransparent region was due to the surface roughness and thickness, and the existing phases did not contribute to the variations of emissivity in this region. 
The emissivity averages of long wavelength infrared (LWIR) region $(8-15 \mu \mathrm{m})$ were $88.4,88.6,88.6$, and $89.4 \%$ for the MAO alumina ceramics prepared at anodic current densities of $10.94,14.58,21.88$, and $43.75 \mathrm{~A} / \mathrm{dm}^{2}$, respectively. The anodic current density did not change the LWIR emissivity significantly, which has a good application in the industrial field to fabricate a relatively high emitter MAO alumina ceramic surface which also provides a strong adhesion to the aluminium substrate, corrosion resistance, wear resistance, thermal shock resistance, and high hardness as found in previously published works. The high emitter MAO alumina ceramic will enhance the heat dissipation of different cooling and heating systems which use aluminium, such as LED, laser, electronic circuits, CPU heat sink, vehicle, indoor radiators, and others. Further works are needed to study the IR emissivity of different MAO alumina ceramics fabricated on the aluminium surfaces using different MAO treatment conditions and electrolyte compositions.

\section{Conclusions}

The increment of anodic current density widened the volcano-like microstructures and lowered its density, while the relatively occupied area by the volcano-like microstructures was approximately constant.

The high anodic current density thickened and roughened the MAO alumina ceramic. The major phases in the MAO alumina ceramic were $\alpha$-alumina, $\gamma$-alumina, sillimanite, and cristobalite. The increment of current density, from $10.94 \mathrm{~A} / \mathrm{dm}^{2}$ to $43.75 \mathrm{~A} / \mathrm{dm}^{2}$, increased the concentration of $\alpha$-alumina from $3.9 \mathrm{wt} . \%$ to $27.6 \mathrm{wt} . \%$ and decreased the concentration of $\gamma$-alumina from $66.6 \mathrm{wt}$. $\%$ to $26.2 \mathrm{wt} . \%$. For $J_{a} \geq$ $14.58 \mathrm{~A} / \mathrm{dm}^{2}$, the sillimanite and cristobalite concentrations were approximately constant around $40 \mathrm{wt} \%$ and less than 5 wt.\%, respectively.

The spectral IR emissivity was slightly varied in the semitransparent region, whereas no significant variation occurred in the opaque region. The slight variation of the emissivity in the semitransparent region was due to the surface roughness and thickness, and the existing phases did not contribute to the variations of emissivity in the semitransparent region. The existing phases contributed to enhancing the emissivity in the opaque region. The apparent peaks centered at $10.2 \mu \mathrm{m}$ and $12.8 \mu \mathrm{m}$ were formed by the cristobalite and sillimanite phases, while another peak at $15.5 \mu \mathrm{m}$ was formed by the $\alpha$ alumina and cristobalite phases.

Using an ecofriendly alkaline silicate electrolyte, a relatively high emissivity MAO alumina ceramic was fabricated on the aluminium substrate. The MAO alumina ceramic has an emissivity peak of $97 \%$ at $12.8 \mu \mathrm{m}$, measured at $70^{\circ} \mathrm{C}$, and an average of LWIR emissivity ranged between $88.4 \%$ and $89.4 \%$. More future studies are required to fabricate high emissivity ceramic surfaces using different MAO processing conditions and electrolytes.

\section{Acknowledgments}

The authors wish to express their sincere gratitude to Dr. Hong-Jen Li for his cooperation and help in using FTIR spectroscopy. The technical support of Shi-Rui Li, Shu-Wei Huang, Yuan-Yi Sung, Chan-Hsuan Chen, Shi-Chung Chen, Wei-Tie Wu, Chien-Huang Kuo, Chih-Yeh Lin, Jie-Mine $\mathrm{Wu}$, and Wan-Yi Chen is gratefully acknowledged. Also, the authors wish to thank Asian Vital Component Company, Taipei, for providing the aluminium pieces.

\section{References}

[1] A. K. A. Shati, S. G. Blakey, and S. B. M. Beck, "The effect of surface roughness and emissivity on radiator output," Energy and Buildings, vol. 43, no. 2-3, pp. 400-406, 2011.

[2] S.-H. Yu, D. Jang, and K.-S. Lee, "Effect of radiation in a radial heat sink under natural convection," International Journal of Heat and Mass Transfer, vol. 55, no. 1-3, pp. 505-509, 2012.

[3] F. Mécuson, T. Czerwiec, T. Belmonte, L. Dujardin, A. Viola, and G. Henrion, "Diagnostics of an electrolytic microarc process for aluminium alloy oxidation," Surface and Coatings Technology, vol. 200, no. 1-4, pp. 804-808, 2005.

[4] S. Stojadinovic, R. Vasilic, I. Belca et al., "Characterization of the plasma electrolytic oxidation of aluminium in sodium tungstate," Corrosion Science, vol. 52, no. 10, pp. 3258-3265, 2010.

[5] Z. Wang, L. Wu, Y. Qi, W. Cai, and Z. Jiang, "Self-lubricating $\mathrm{Al}_{2} \mathrm{O}_{3}$ /PTFE composite coating formation on surface of aluminium alloy," Surface and Coatings Technology, vol. 204, no. 20, pp. 3315-3318, 2010.

[6] R. H. U. Khan, A. Yerokhin, X. Li, H. Dong, and A. Matthews, "Surface characterisation of DC plasma electrolytic oxidation treated 6082 aluminium alloy: effect of current density and electrolyte concentration," Surface and Coatings Technology, vol. 205, no. 6, pp. 1679-1688, 2010.

[7] L. O. Snizhko, A. L. Yerokhin, A. Pilkington et al., "Anodic processes in plasma electrolytic oxidation of aluminium in alkaline solutions," Electrochimica Acta, vol. 49, no. 13, pp. 2085-2095, 2004.

[8] S.-M. Moon and S.-I. Pyun, "The corrosion of pure aluminium during cathodic polarization in aqueous solutions," Corrosion Science, vol. 39, no. 2, pp. 399-408, 1997.

[9] L. Wen, Y. Wang, Y. Zhou, J.-H. Ouyang, L. Guo, and D. Jia, "Corrosion evaluation of microarc oxidation coatings formed on 2024 aluminium alloy," Corrosion Science, vol. 52, no. 8, pp. 2687-2696, 2010.

[10] J. R. Morlidge, P. Skeldon, G. E. Thompson, H. Habazaki, K. Shimizu, and G. C. Wood, "Gel formation and the efficiency of anodic film growth on aluminium," Electrochimica Acta, vol. 44, no. 14, pp. 2423-2435, 1999.

[11] P. I. Butyagin, Y. V. Khokhryakov, and A. I. Mamaev, "Microplasma systems for creating coatings on aluminium alloys," Materials Letters, vol. 57, no. 11, pp. 1748-1751, 2003.

[12] J. Jovović, S. Stojadinović, N. M. Šišović, and N. Konjević, "Spectroscopic characterization of plasma during electrolytic oxidation (PEO) of aluminium," Surface and Coatings Technology, vol. 206, pp. 24-28, 2011.

[13] A. L. Yerokhin, L. O. Snizhko, N. L. Gurevina, A. Leyland, A. Pilkington, and A. Matthews, "Spatial characteristics of discharge phenomena in plasma electrolytic oxidation of aluminium alloy," Surface and Coatings Technology, vol. 177-178, pp. 779-783, 2004.

[14] T. Abdulla, A. Yerokhin, and R. Goodall, "Effect of Plasma Electrolytic Oxidation coating on the specific strength of open-cell 
aluminium foams," Materials and Design, vol. 32, no. 7, pp. 37423749, 2011.

[15] A. L. Yerokhin, A. A. Voevodin, V. V. Lyubimov, J. Zabinski, and M. Donley, "Plasma electrolytic fabrication of oxide ceramic surface layers for tribotechnical purposes on aluminium alloys," Surface and Coatings Technology, vol. 110, no. 3, pp. 140-146, 1998.

[16] E. Matykina, R. Arrabal, P. Skeldon, G. E. Thompson, and P. Belenguer, "AC PEO of aluminium with porous alumina precursor films," Surface and Coatings Technology, vol. 205, no. 6, pp. 1668-1678, 2010.

[17] S. V. Gnedenkov, O. A. Khrisanfova, A. G. Zavidnaya et al., "Production of hard and heat-resistant coatings on aluminium using a plasma micro-discharge," Surface and Coatings Technology, vol. 123, no. 1, pp. 24-28, 2000.

[18] M. Treviño, N. F. Garza-Montes-de-Oca, A. Pérez, M. A. L. Hernández-Rodríguez, A. Juárez, and R. Colás, "Wear of an aluminium alloy coated by plasma electrolytic oxidation," Surface and Coatings Technology, vol. 206, no. 8-9, pp. 2213-2219, 2012.

[19] T. S. Lim, H. S. Ryu, and S.-H. Hong, "Electrochemical corrosion properties of $\mathrm{CeO}_{2}$-containing coatings on AZ31 magnesium alloys prepared by plasma electrolytic oxidation," Corrosion Science, vol. 62, pp. 104-111, 2012.

[20] A. V. Timoshenko and Y. V. Magurova, "Investigation of plasma electrolytic oxidation processes of magnesium alloy MA2-1 under pulse polarisation modes," Surface and Coatings Technology, vol. 199, no. 2-3, pp. 135-140, 2005.

[21] J. Liang, P. B. Srinivasan, C. Blawert, and W. Dietzel, "Comparison of electrochemical corrosion behaviour of $\mathrm{MgO}$ and $\mathrm{ZrO}_{2}$ coatings on AM50 magnesium alloy formed by plasma electrolytic oxidation," Corrosion Science, vol. 51, no. 10, pp. 2483-2492, 2009.

[22] F. Liu, D. Shan, Y. Song, E.-H. Han, and W. Ke, "Corrosion behavior of the composite ceramic coating containing zirconium oxides on AM30 magnesium alloy by plasma electrolytic oxidation," Corrosion Science, vol. 53, no. 11, pp. 3845-3852, 2011.

[23] G.-H. Lv, H. Chen, L. Li et al., "Investigation of plasma electrolytic oxidation process on AZ91D magnesium alloy," Current Applied Physics, vol. 9, no. 1, pp. 126-130, 2009.

[24] P. Bala Srinivasan, R. Zettler, C. Blawert, and W. Dietzel, "A study on the effect of plasma electrolytic oxidation on the stress corrosion cracking behaviour of a wrought AZ61 magnesium alloy and its friction stir weldment," Materials Characterization, vol. 60, no. 5, pp. 389-396, 2009.

[25] P. Zhang, X. Nie, H. Hu, and Y. Liu, “TEM analysis and tribological properties of Plasma Electrolytic Oxidation (PEO) coatings on a magnesium engine AJ62 alloy," Surface and Coatings Technology, vol. 205, no. 5, pp. 1508-1514, 2010.

[26] F. Liu, D. Shan, Y. Song, and E.-H. Han, "Effect of additives on the properties of plasma electrolytic oxidation coatings formed on AM50 magnesium alloy in electrolytes containing K2ZrF6," Surface and Coatings Technology, vol. 206, no. 2-3, pp. 455-463, 2011.

[27] P. Wang, J. Li, Y. Guo, and Z. Yang, "Growth process and corrosion resistance of ceramic coatings of micro-arc oxidation on Mg-Gd-Y magnesium alloys," Journal of Rare Earths, vol. 28, no. 5, pp. 798-802, 2010.

[28] J. Liang, L. Hu, and J. Hao, "Characterization of microarc oxidation coatings formed on AM60B magnesium alloy in silicate and phosphate electrolytes," Applied Surface Science, vol. 253, no. 10, pp. 4490-4496, 2007.
[29] F. Jin, P. K. Chu, G. Xu, J. Zhao, D. Tang, and H. Tong, "Structure and mechanical properties of magnesium alloy treated by micro-arc discharge oxidation using direct current and highfrequency bipolar pulsing modes," Materials Science and Engineering A, vol. 435-436, pp. 123-126, 2006.

[30] K. R. Shin, Y. G. Ko, and D. H. Shin, "Effect of electrolyte on surface properties of pure titanium coated by plasma electrolytic oxidation," Journal of Alloys and Compounds, vol. 509, supplement 1, pp. S478-S481, 2011.

[31] X. Wang, X. Pan, W. Ye, Y. Wei, and Y. Chen, "Preparation and properties of $\mathrm{TiC}_{x} \mathrm{~N}_{1-x}$ coatings containing calcium on titanium surface by plasma electrolytic carbonitriding," Surface and Coatings Technology, vol. 228, supplement 1, pp. S194-S197, 2013.

[32] D. Wei, Y. Zhou, Y. Wang, and D. Jia, "Characteristic of microarc oxidized coatings on titanium alloy formed in electrolytes containing chelate complex and nano-HA," Applied Surface Science, vol. 253, no. 11, pp. 5045-5050, 2007.

[33] W. Zhang, K. Du, C. Yan, and F. Wang, "Preparation and characterization of a novel Si-incorporated ceramic film on pure titanium by plasma electrolytic oxidation," Applied Surface Science, vol. 254, no. 16, pp. 5216-5223, 2008.

[34] K. R. Shin, Y. G. Ko, and D. H. Shin, "Surface characteristics of $\mathrm{ZrO}_{2}$-containing oxide layer in titanium by plasma electrolytic oxidation in $\mathrm{K}_{4} \mathrm{P}_{2} \mathrm{O}_{7}$ electrolyte," Journal of Alloys and Compounds, vol. 536, supplement 1, pp. S226-S230, 2012.

[35] Y. M. Wang, L. X. Guo, J. H. Ouyang, Y. Zhou, and D. C. Jia, "Interface adhesion properties of functional coatings on titanium alloy formed by microarc oxidation method," Applied Surface Science, vol. 255, no. 15, pp. 6875-6880, 2009.

[36] P. Huang, K.-W. Xu, and Y. Han, "Preparation and apatite layer formation of plasma electrolytic oxidation film on titanium for biomedical application," Materials Letters, vol. 59, no. 2-3, pp. 185-189, 2005.

[37] Y. Wang, T. Lei, L. Guo, and B. Jiang, "Fretting wear behaviour of microarc oxidation coatings formed on titanium alloy against steel in unlubrication and oil lubrication," Applied Surface Science, vol. 252, no. 23, pp. 8113-8120, 2006.

[38] S. Stojadinović, R. Vasilić, M. Petković, and L. Zeković, "Plasma electrolytic oxidation of titanium in heteropolytungstate acids," Surface and Coatings Technology, vol. 206, pp. 575-581, 2011.

[39] H. Tang, Q. Sun, T. Xin, C. Yi, Z. Jiang, and F. Wang, "Influence of $\mathrm{Co}\left(\mathrm{CH}_{3} \mathrm{COO}\right)_{2}$ concentration on thermal emissivity of coatings formed on titanium alloy by micro-arc oxidation," Current Applied Physics, vol. 12, no. 1, pp. 284-290, 2012.

[40] S. Cui, J. Han, Y. Du, and W. Li, "Corrosion resistance and wear resistance of plasma electrolytic oxidation coatings on metal matrix composites," Surface and Coatings Technology, vol. 201, no. 9-11, pp. 5306-5309, 2007.

[41] G. Rapheal, S. Kumar, C. Blawert, and N. B. Dahotre, "Wear behavior of plasma electrolytic oxidation (PEO) and hybrid coatings of PEO and laser on MRI 230D magnesium alloy," Wear, vol. 271, no. 9-10, pp. 1987-1997, 2011.

[42] X. Nie, E. I. Meletis, J. C. Jiang, A. Leyland, A. L. Yerokhin, and A. Matthews, "Abrasive wear/corrosion properties and TEM analysis of $\mathrm{Al}_{2} \mathrm{O}_{3}$ coatings fabricated using plasma electrolysis," Surface and Coatings Technology, vol. 149, no. 2-3, pp. 245-251, 2002.

[43] Y. Jiang, Y. Zhang, Y. Bao, and K. Yang, "Sliding wear behaviour of plasma electrolytic oxidation coating on pure aluminium," Wear, vol. 271, no. 9-10, pp. 1667-1670, 2011. 
[44] M. Aliofkhazraei, A. Sabour Rouhaghdam, and T. Shahrabi, "Abrasive wear behaviour of $\mathrm{Si}_{3} \mathrm{~N}_{4} / \mathrm{TiO}_{2}$ nanocomposite coatings fabricated by plasma electrolytic oxidation," Surface and Coatings Technology, vol. 205, supplement 1, pp. S41-S46, 2010.

[45] T. Wei, F. Yan, and J. Tian, "Characterization and wear- and corrosion-resistance of microarc oxidation ceramic coatings on aluminum alloy," Journal of Alloys and Compounds, vol. 389, no. 1-2, pp. 169-176, 2005.

[46] L. Wang, J. Zhou, J. Liang, and J. Chen, "Microstructure and corrosion behavior of plasma electrolytic oxidation coated magnesium alloy pre-treated by laser surface melting," Surface and Coatings Technology, vol. 206, no. 13, pp. 3109-3115, 2012.

[47] P. Su, X. Wu, Y. Guo, and Z. Jiang, "Effects of cathode current density on structure and corrosion resistance of plasma electrolytic oxidation coatings formed on ZK60 Mg alloy," Journal of Alloys and Compounds, vol. 475, no. 1-2, pp. 773-777, 2009.

[48] R. O. Hussein, D. O. Northwood, and X. Nie, “The influence of pulse timing and current mode on the microstructure and corrosion behaviour of a plasma electrolytic oxidation (PEO) coated AM60B magnesium alloy," Journal of Alloys and Compounds, vol. 541, pp. 41-48, 2012.

[49] L. Rama Krishna, G. Poshal, and G. Sundararajan, "Influence of electrolyte chemistry on morphology and corrosion resistance of micro arc oxidation coatings deposited on magnesium," Metallurgical and Materials Transactions A, vol. 41, no. 13, pp. 34993508, 2010.

[50] J. Liang, L. Hu, and J. Hao, "Improvement of corrosion properties of microarc oxidation coating on magnesium alloy by optimizing current density parameters," Applied Surface Science, vol. 253, no. 16, pp. 6939-6945, 2007.

[51] C. Blawert, V. Heitmann, W. Dietzel, H. M. Nykyforchyn, and M. D. Klapkiv, "Influence of electrolyte on corrosion properties of plasma electrolytic conversion coated magnesium alloys," Surface and Coatings Technology, vol. 201, no. 21, pp. 8709-8714, 2007.

[52] D. Y. Hwang, Y. M. Kim, D.-Y. Park, B. Yoo, and D. H. Shin, "Corrosion resistance of oxide layers formed on AZ91 Mg alloy in $\mathrm{KMnO}_{4}$ electrolyte by plasma electrolytic oxidation," Electrochimica Acta, vol. 54, no. 23, pp. 5479-5485, 2009.

[53] Y. M. Wang, B. L. Jiang, T. Q. Lei, and L. X. Guo, "Microarc oxidation coatings formed on Ti6Al4 $\mathrm{V}$ in $\mathrm{Na}_{2} \mathrm{SiO}_{3}$ system solution: microstructure, mechanical and tribological properties," Surface and Coatings Technology, vol. 201, no. 1-2, pp. 82-89, 2006.

[54] J. Liang, B. Guo, J. Tian, H. Liu, J. Zhou, and T. Xu, "Effect of potassium fluoride in electrolytic solution on the structure and properties of microarc oxidation coatings on magnesium alloy," Applied Surface Science, vol. 252, no. 2, pp. 345-351, 2005.

[55] Y. Guangliang, L. Xianyi, B. Yizhen, C. Haifeng, and J. Zengsun, "The effects of current density on the phase composition and microstructure properties of micro-arc oxidation coating," Journal of Alloys and Compounds, vol. 345, no. 1-2, pp. 196-200, 2002.

[56] C.-C. Tseng, J.-L. Lee, T.-H. Kuo, S.-N. Kuo, and K.-H. Tseng, "The influence of sodium tungstate concentration and anodizing conditions on microarc oxidation (MAO) coatings for aluminum alloy," Surface and Coatings Technology, vol. 206, no. 16, pp. 3437-3443, 2012.

[57] H. J. Robinson, A. E. Markaki, C. A. Collier, and T. W. Clyne, "Cell adhesion to plasma electrolytic oxidation (PEO) titania coatings, assessed using a centrifuging technique," Journal of the Mechanical Behavior of Biomedical Materials, vol. 4, no. 8, pp. 2103-2112, 2011.

[58] S. V. Gnedenkov, O. A. Khrisanfova, A. G. Zavidnaya et al., "Composition and adhesion of protective coatings on aluminum," Surface and Coatings Technology, vol. 145, no. 1-3, pp. 146-151, 2001.

[59] K. Ramachandran, V. Selvarajan, P. V. Ananthapadmanabhan, and K. P. Sreekumar, "Microstructure, adhesion, microhardness, abrasive wear resistance and electrical resistivity of the plasma sprayed alumina and alumina-titania coatings," Thin Solid Films, vol. 315, no. 1-2, pp. 144-152, 1998.

[60] Y. Wang, Z. Jiang, and Z. Yao, "Microstructure, bonding strength and thermal shock resistance of ceramic coatings on steels prepared by plasma electrolytic oxidation," Applied Surface Science, vol. 256, no. 3, pp. 650-656, 2009.

[61] Y. Xu, Z. Yao, F. Jia, Y. Wang, Z. Jiang, and H. Bu, "Preparation of PEO ceramic coating on Ti alloy and its high temperature oxidation resistance," Current Applied Physics, vol. 10, no. 2, pp. 698-702, 2010.

[62] Y. Wang, Z. Jiang, and Z. Yao, "Formation of titania composite coatings on carbon steel by plasma electrolytic oxidation," Applied Surface Science, vol. 256, no. 20, pp. 5818-5823, 2010.

[63] J. Ding, J. Liang, L. Hu, J. Hao, and Q. Xue, "Effects of sodium tungstate on characteristics of microarc oxidation coatings formed on magnesium alloy in silicate- $\mathrm{KOH}$ electrolyte," Transactions of Nonferrous Metals Society of China, vol. 17, no. 2, pp. 244-249, 2007.

[64] M. Tang, H. Liu, W. Li, and L. Zhu, "Effect of zirconia sol in electrolyte on the characteristics of microarc oxidation coating on AZ91D magnesium," Materials Letters, vol. 65, no. 3, pp. 413415, 2011.

[65] Q. Cai, L. Wang, B. Wei, and Q. Liu, "Electrochemical performance of microarc oxidation films formed on AZ91D magnesium alloy in silicate and phosphate electrolytes," Surface and Coatings Technology, vol. 200, no. 12-13, pp. 3727-3733, 2006.

[66] C.-E. Barchiche, E. Rocca, and J. Hazan, "Corrosion behaviour of Sn-containing oxide layer on AZ91D alloy formed by plasma electrolytic oxidation," Surface and Coatings Technology, vol. 202, no. 17, pp. 4145-4152, 2008.

[67] M. Tang, W. Li, H. Liu, and L. Zhu, "Preparation $\mathrm{Al}_{2} \mathrm{O}_{3} / \mathrm{ZrO}_{2}$ composite coating in an alkaline phosphate electrolyte containing $\mathrm{K}_{2} \mathrm{ZrF}_{6}$ on aluminum alloy by microarc oxidation," Applied Surface Science, vol. 258, no. 15, pp. 5869-5875, 2012.

[68] M. Tang, W. Li, H. Liu, and L. Zhu, "Influence of titania sol in the electrolyte on characteristics of the microarc oxidation coating formed on 2A70 aluminum alloy," Surface and Coatings Technology, vol. 205, no. 17-18, pp. 4135-4140, 2011.

[69] E. Matykina, R. Arrabal, P. Skeldon, and G. E. Thompson, "Investigation of the growth processes of coatings formed by AC plasma electrolytic oxidation of aluminium," Electrochimica Acta, vol. 54, no. 27, pp. 6767-6778, 2009.

[70] V. Raj and M. Mubarak Ali, "Formation of ceramic alumina nanocomposite coatings on aluminium for enhanced corrosion resistance," Journal of Materials Processing Technology, vol. 209, no. 12-13, pp. 5341-5352, 2009.

[71] C. S. Dunleavy, J. A. Curran, and T. W. Clyne, "Self-similar scaling of discharge events through PEO coatings on aluminium," Surface and Coatings Technology, vol. 206, no. 6, pp. 1051-1061, 2011.

[72] M. Montazeri, C. Dehghanian, M. Shokouhfar, and A. Baradaran, "Investigation of the voltage and time effects on the formation of hydroxyapatite-containing titania prepared by plasma 
electrolytic oxidation on Ti-6Al-4V alloy and its corrosion behavior," Applied Surface Science, vol. 257, no. 16, pp. 72687275, 2011.

[73] W. Xue, Q. Zhu, Q. Jin, and M. Hua, "Characterization of ceramic coatings fabricated on zirconium alloy by plasma electrolytic oxidation in silicate electrolyte," Materials Chemistry and Physics, vol. 120, no. 2-3, pp. 656-660, 2010.

[74] J. Li, H. Cai, X. Xue, and B. Jiang, "The outward-inward growth behavior of microarc oxidation coatings in phosphate and silicate solution," Materials Letters, vol. 64, no. 19, pp. 2102-2104, 2010.

[75] G. Sundararajan and L. Rama Krishna, "Mechanisms underlying the formation of thick alumina coatings through the MAO coating technology," Surface and Coatings Technology, vol. 167, no. 2-3, pp. 269-277, 2003.

[76] H. Habazaki, S. Tsunekawa, E. Tsuji, and T. Nakayama, "Formation and characterization of wear-resistant PEO coatings formed on $\beta$-titanium alloy at different electrolyte temperatures," Applied Surface Science, vol. 259, pp. 711-718, 2012.

[77] E. V. Parfenov, R. R. Nevyantseva, and S. A. Gorbatkov, "Process control for plasma electrolytic removal of TiN coatings. Part 1: duration control," Surface and Coatings Technology, vol. 199, no. 2-3, pp. 189-197, 2005.

[78] P. Huang, F. Wang, K. Xu, and Y. Han, "Mechanical properties of titania prepared by plasma electrolytic oxidation at different voltages," Surface and Coatings Technology, vol. 201, no. 9-11, pp. 5168-5171, 2007.

[79] D. Wei, Y. Zhou, D. Jia, and Y. Wang, "Effect of applied voltage on the structure of microarc oxidized $\mathrm{TiO}_{2}$-based bioceramic films," Materials Chemistry and Physics, vol. 104, no. 1, pp. 177182, 2007.

[80] H. Wu, X. Lu, B. Long, X. Wang, J. Wang, and Z. Jin, “The effects of cathodic and anodic voltages on the characteristics of porous nanocrystalline titania coatings fabricated by microarc oxidation," Materials Letters, vol. 59, no. 2-3, pp. 370-375, 2005.

[81] C. B. Wei, X. B. Tian, S. Q. Yang, X. B. Wang, R. K. Y. Fu, and P. K. Chu, "Anode current effects in plasma electrolytic oxidation," Surface and Coatings Technology, vol. 201, no. 9-11, pp. 50215024, 2007.

[82] X.-M. Zhang, X.-B. Tian, C.-Z. Gong, and S.-Q. Yang, "Effects of current density on coating kinetic and micro-structure of microarc oxidation coatings fabricated on pure aluminum," in Proceedings of the 3rd IEEE International Nanoelectronics Conference (INEC '10), pp. 1482-1483, January 2010.

[83] X. Sun, Z. Jiang, Z. Yao, and X. Zhang, "The effects of anodic and cathodic processes on the characteristics of ceramic coatings formed on titanium alloy through the MAO coating technology," Applied Surface Science, vol. 252, no. 2, pp. 441-447, 2005.

[84] P. Bala Srinivasan, J. Liang, R. G. Balajeee, C. Blawert, M. Störmer, and W. Dietzel, "Effect of pulse frequency on the microstructure, phase composition and corrosion performance of a phosphate-based plasma electrolytic oxidation coated AM50 magnesium alloy," Applied Surface Science, vol. 256, no. 12, pp. 3928-3935, 2010.

[85] Z. Yao, Y. Liu, Y. Xu, Z. Jiang, and F. Wang, "Effects of cathode pulse at high frequency on structure and composition of $\mathrm{Al}_{2} \mathrm{TiO}_{5}$ ceramic coatings on $\mathrm{Ti}$ alloy by plasma electrolytic oxidation," Materials Chemistry and Physics, vol. 126, no. 1-2, pp. 227-231, 2011.
[86] P. Gupta, G. Tenhundfeld, E. O. Daigle, and D. Ryabkov, "Electrolytic plasma technology: science and engineering-an overview," Surface and Coatings Technology, vol. 201, no. 21, pp. 8746-8760, 2007.

[87] Y. M. Wang, H. Tian, X. E. Shen et al., "An elevated temperature infrared emissivity ceramic coating formed on 2024 aluminium alloy by microarc oxidation," Ceramics International, vol. 39, pp. 2869-2875, 2013.

[88] Z. W. Wang, Y. M. Wang, Y. Liu et al., "Microstructure and infrared emissivity property of coating containing $\mathrm{TiO}_{2}$ formed on titanium alloy by microarc oxidation," Current Applied Physics, vol. 11, no. 6, pp. 1405-1409, 2011.

[89] P. M. de Woolf and J. W. Visser, "Absolute Intensities-outline of a recommended practice," Powder Diffraction, vol. 3, pp. 202204, 1988.

[90] E. P. G. T. van de Ven and H. Koelmans, "The cathodic corrosion of Aluminum," Journal of The Electrochemical Society, vol. 123, pp. 143-144, 1976.

[91] E. V. Koroleva, G. E. Thompson, G. Hollrigl, and M. Bloeck, "Surface morphological changes of aluminium alloys in alkaline solution: effect of second phase material," Corrosion Science, vol. 41, no. 8, pp. 1475-1495, 1999.

[92] C. Zhu, P. Lu, Z. Zheng, and J. Ganor, "Coupled alkali feldspar dissolution and secondary mineral precipitation in batch systems: 4. Numerical modeling of kinetic reaction paths," Geochimica et Cosmochimica Acta, vol. 74, no. 14, pp. 3963-3983, 2010.

[93] Y. K. Pan, C. Z. Chen, D. G. Wang, X. Yu, and Z. Q. Lin, "Influence of additives on microstructure and property of microarc oxidized Mg-Si-O coatings," Ceramics International, vol. 38, pp. 5527-5533, 2012.

[94] R. McPherson, "Formation of metastable phases in flame- and plasma-prepared alumina," Journal of Materials Science, vol. 8, no. 6, pp. 851-858, 1973.

[95] P. S. Santos, H. S. Santos, and S. P. Toledo, "Standard transition aluminas. Electron microscopy studies," Materials Research, vol. 3, pp. 104-114, 2000.

[96] R. K. Iler, Chemistry of Silica-Solubility, Polymerization, Colloid and Surface Properties and Biochemistry, chapter 1, John Wiley \& Sons, 1979.

[97] L. Rama Krishna, K. R. C. Somaraju, and G. Sundararajan, "The tribological performance of ultra-hard ceramic composite coatings obtained through microarc oxidation," Surface and Coatings Technology, vol. 163-164, pp. 484-490, 2003.

[98] F.-Y. Jin, K. Wang, M. Zhu et al., "Infrared reflection by alumina films produced on aluminum alloy by plasma electrolytic oxidation," Materials Chemistry and Physics, vol. 114, no. 1, pp. 398-401, 2009.

[99] K. Wang, B.-H. Koo, C.-G. Lee, Y.-J. Kim, S.-H. Lee, and E. Byon, "Effects of electrolytes variation on formation of oxide layers of $6061 \mathrm{Al}$ alloys by plasma electrolytic oxidation," Transactions of Nonferrous Metals Society of China, vol. 19, no. 4, pp. 866-870, 2009.

[100] G. E. Walrafen and E. Pugh, "Raman combinations and stretching overtones from water, heavy water, and $\mathrm{NaCl}$ in water at shifts to ca. $7000 \mathrm{~cm}-1$," Journal of Solution Chemistry, vol. 33, no. 1, pp. 81-97, 2004.

[101] S. P. Langley, "XXII. The selective absorption of solar energy," Philosophical Magazine Series 5, vol. 15, no. 93, pp. 153-183, 1883.

[102] R. D. Aines and G. R. Rossman, "The high temperature behavior of water and carbon dioxide in cordierite and beryl," American Mineralogist, vol. 69, no. 3-4, pp. 319-327, 1984. 
[103] H. Rubens and E. Aschkinass, "Observations on the absorption and emission of aqueous vapor and carbon dioxide in the infrared spectrum," The Astrophysical Journal, vol. 8, p. 176, 1898.

[104] J. Ryczkowski, "IR spectroscopy in catalysis," Catalysis Today, vol. 68, no. 4, pp. 263-381, 2001.

[105] K. M. Lee, B. U. Lee, S. I. Yoon, E. S. Lee, B. Yoo, and D. H. Shin, "Evaluation of plasma temperature during plasma oxidation processing of AZ91 Mg alloy through analysis of the melting behavior of incorporated particles," Electrochimica Acta, vol. 67, pp. 6-11, 2012.

[106] R. O. Hussein, X. Nie, D. O. Northwood, A. Yerokhin, and A. Matthews, "Spectroscopic study of electrolytic plasma and discharging behaviour during the plasma electrolytic oxidation (PEO) process," Journal of Physics D, vol. 43, no. 10, Article ID 105203, 2010.

[107] Y. Wang, Z. Jiang, X. Liu, and Z. Yao, "Influence of treating frequency on microstructure and properties of $\mathrm{Al}_{2} \mathrm{O}_{3}$ coating on 304 stainless steel by cathodic plasma electrolytic deposition," Applied Surface Science, vol. 255, no. 21, pp. 8836-8840, 2009.

[108] O. Rozenbaum, D. De Sousa Meneses, and P. Echegut, "Texture and porosity effects on the thermal radiative behavior of alumina ceramics," International Journal of Thermophysics, vol. 30, no. 2, pp. 580-590, 2009.

[109] A. Boumaza, L. Favaro, J. Lédion et al., "Transition alumina phases induced by heat treatment of boehmite: an X-ray diffraction and infrared spectroscopy study," Journal of Solid State Chemistry, vol. 182, no. 5, pp. 1171-1176, 2009.

[110] T. Morioka, S. Kimura, N. Tsuda, C. Kaito, Y. Saito, and C. Koike, "Study of the structure of silica film by infrared spectroscopy and electron diffraction analyses," Monthly Notices of the Royal Astronomical Society, vol. 299, no. 1, pp. 78-82, 1998.

[111] C. H. Rüscher, “Thermic transformation of sillimanite single crystals to 3:2 mullite plus melt: Investigations by polarized IRreflection micro spectroscopy," Journal of the European Ceramic Society, vol. 21, no. 14, pp. 2463-2469, 2001.

[112] K. Nouneh, I. V. Kityk, R. Viennois et al., "Influence of an electron-phonon subsystem on specific heat and two-photon absorption of the semimagnetic semiconductors $\mathrm{Pb}_{1-x} \mathrm{Yb}_{x} \mathrm{X}$ $(\mathrm{X}=\mathrm{S}, \mathrm{Se}, \mathrm{Te})$ near the semiconductor-isolator phase transformation," Physical Review B, vol. 73, no. 3, Article ID 035329, 2006. 

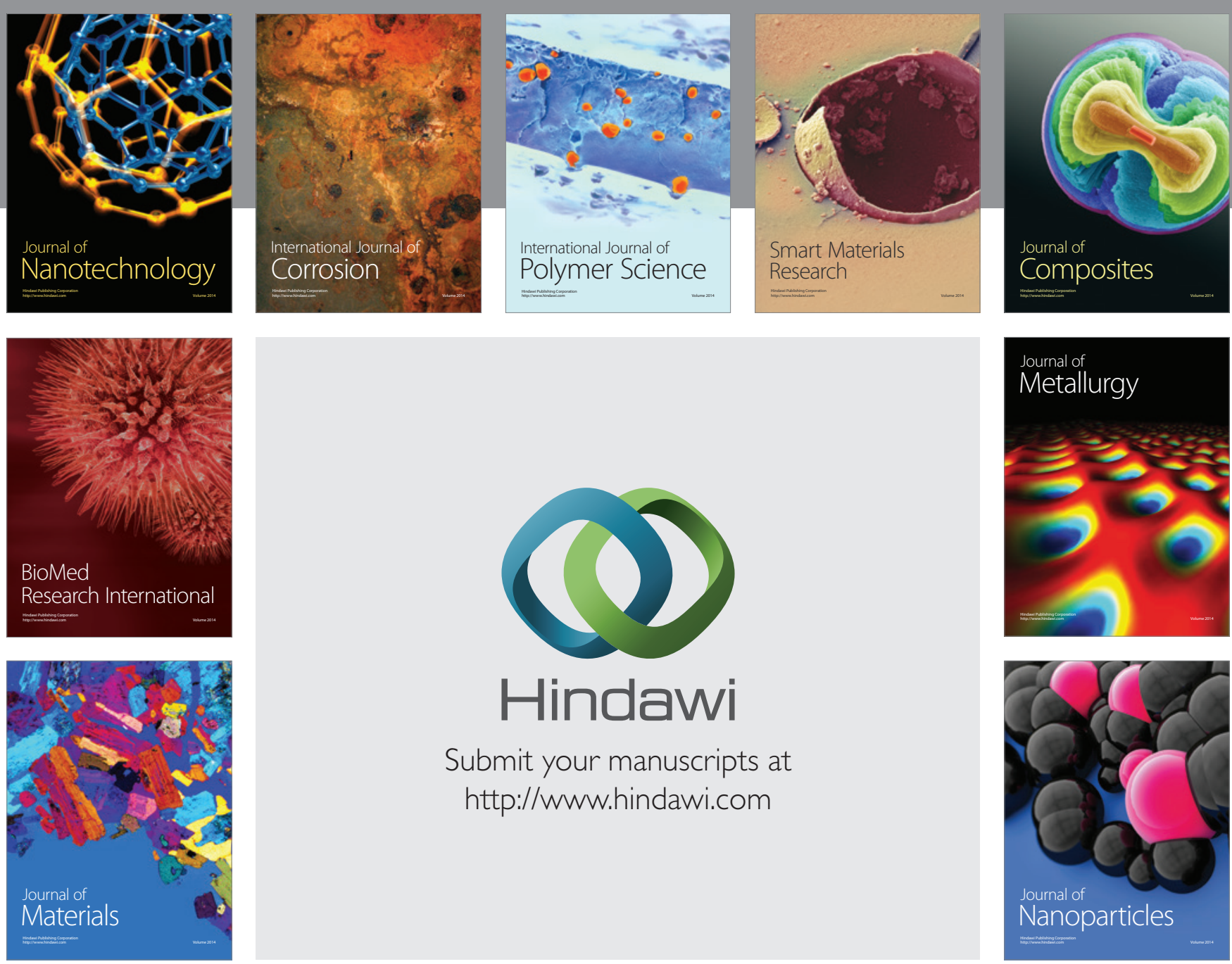

Submit your manuscripts at http://www.hindawi.com
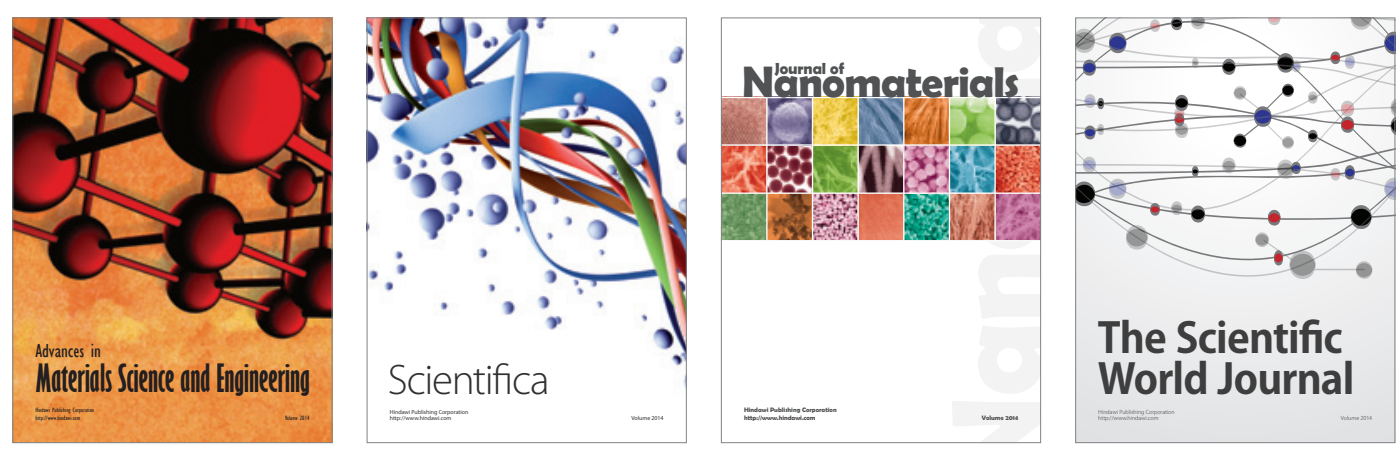

\section{The Scientific World Journal}
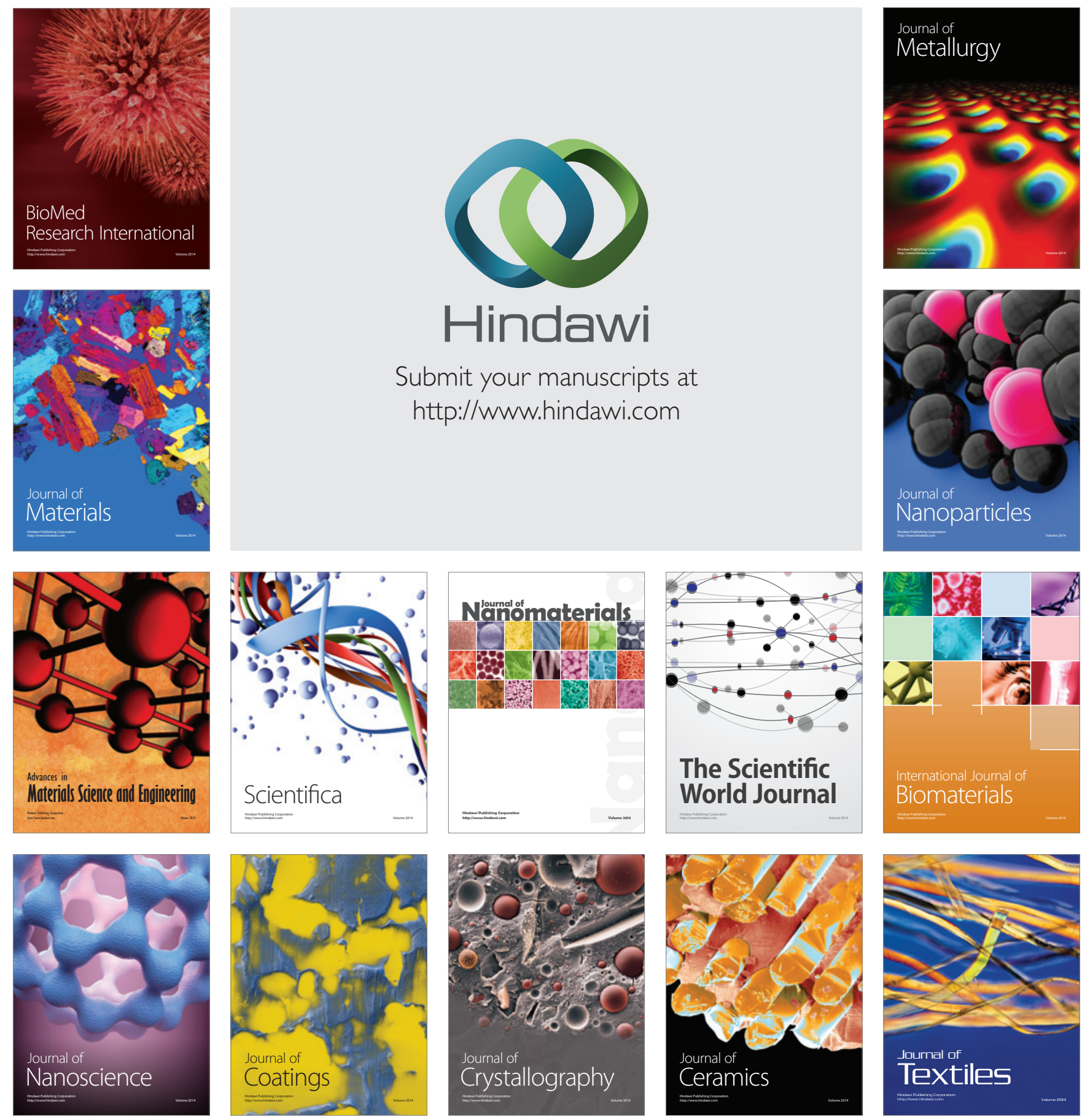